\title{
Reaction-driven casing expansion: potential for wellbore leakage mitigation
}

\author{
Timotheus K. T. Wolterbeek ${ }^{1} \cdot$ Reinier van Noort ${ }^{1,2} \cdot$ Christopher J. Spiers $^{1}$
}

Received: 20 January 2017/Accepted: 14 March 2017/Published online: 1 April 2017

(c) The Author(s) 2017. This article is published with open access at Springerlink.com

\begin{abstract}
It is generally challenging to predict the postabandonment behaviour and integrity of wellbores. Leakage is, moreover, difficult to mitigate, particularly between the steel casing and outer cement sheath. Radially expanding the casing with some form of internal plug, thereby closing annular voids and fractures around it, offers a possible solution to both issues. However, such expansion requires development of substantial internal stresses. Chemical reactions that involve a solid volume increase and produce a force of crystallisation (FoC), such as $\mathrm{CaO}$ hydration, offer obvious potential. However, while thermodynamically capable of producing stresses in the GPa range, the maximum stress obtainable by $\mathrm{CaO}$ hydration has not been validated or determined experimentally. Here, we report uniaxial compaction/expansion experiments performed in an oedometer-type apparatus on precompacted $\mathrm{CaO}$ powder, at $65^{\circ} \mathrm{C}$ and at atmospheric pore fluid pressure. Using this set-up, the $\mathrm{FoC}$ generated during $\mathrm{CaO}$ hydration could be measured directly. Our results show FoC-induced stresses reaching up to $153 \mathrm{MPa}$, with reaction stopping or slowing down before completion. Failure to achieve the GPa stresses predicted by theory is attributed to competition between FoC development and its inhibiting effect on reaction progress. Microstructural observations indicate that reaction-induced stresses shut down pathways
\end{abstract}

Timotheus K. T. Wolterbeek

t.k.t.wolterbeek@uu.nl

1 HPT Laboratory, Department of Earth Sciences, Utrecht University, Budapestlaan 4, 3584 CD Utrecht, The Netherlands

2 Present Address: Department of Environmental Technology, Institute for Energy Technology, Instituttveien 18, 2007 Kjeller, Norway for water into the sample, hampering ongoing reaction and limiting the magnitude of stress build-up to the values observed. The results nonetheless point the way to understanding the behaviour of such systems and to finding engineering solutions that may allow large controlled stresses and strains to be achieved in wellbore sealing operations in future.

Keywords $\mathrm{CaO}$ - Casing · Force of crystallisation · Hydration - Wellbore integrity

\section{Introduction}

As ageing hydrocarbon fields approach the end of their productive and economic life [63, 81, 125], and as various options for their potential reuse, such as geological storage of $\mathrm{CO}_{2}[3,50,127]$ or of energy [8, 52, 99] emerge, wellbore sealing issues are becoming ever more important $[5,19]$. In particular, effective plug and wellbore sealing procedures, ensuring long-term zonal isolation, are essential (a) for complying with increasingly stringent environmental regulations applying to well and reservoir abandonment [109] and (b) for enabling reuse of reservoirs in future applications [51].

In most existing wells, the borehole is lined with a string of concentric steel tubes (called casings and liners). The tubes are fixed in place and sealed against the wall rock using Portland-based cement [91]. These cement seals are susceptible to various forms of failure [42, 90]. For example, during emplacement, poor removal of drilling mud or filter cake may impair bonding between the cement, the casing and the surrounding rock [1,76]. Moreover, cement shrinkage upon hardening, inherent to some of the processes involved in hydration [117], produces radial 
contraction that may result in tensile fracturing of the cement or debonding at the casing-cement and cementformation interfaces [26, 33]. In addition, fluctuations in temperature and stress state, endured by the wellbore during field operations, may further contribute to the accumulation of structural damage [77, 80, 83, 93, 102].

Regardless of their origin, such defects offer pathways for fluid flow that may compromise well integrity [132]. Indeed, considerable numbers of wells are known to have zonal isolation issues. Analysis of 315,000 oil, gas and injection wells in Alberta showed that $\sim 4.6 \%$ of these wells displayed surface casing vent flow or gas migration [4]. For energy wells completed since 1971, this percentage is higher, with $\sim 14 \%$ exhibiting surface casing vent flow of $>300 \mathrm{~m}^{3}$ day $^{-1}$ [58]. Of 41,381 wells drilled in Pennsylvania between 2000 and 2012, $1.9 \%$ showed some form of structural integrity failure [55]. Moreover, sustained casing pressure (unintended development of pressure at the surface, at the well, which rebuilds after bleeding off) is reported in $\sim 43 \%$ of the producing and abandoned wells located on the outer continental shelf of the Gulf of Mexico [15]. If unwanted fluid migration phenomena such as these progressively impair the well or already exceed the maximum rate allowed by regulations, remedial measures are required.

Squeeze cementing operations are common practice in mitigating leakage occurring behind the casing, i.e. outside of the steel pipe (annular leakage). Squeeze cementing involves perforation of the casing over the defective wellbore interval, followed by injection of cement to seal annular voids and fractures [91]. However, this conventional approach is often ineffective. A performance study of squeeze cementing operations performed on wells in west Texas found that first-attempt remediation was successful in only 47 of 137 cases (34\%), and that the success rate for multiple attempts (up to five per well) was $<60 \%$ [25]. There is therefore substantial interest in alternative approaches to leakage mitigation, such as the casing expansion procedure recently proposed by Kupresan et al. $[74,75]$. This involves permanent radial expansion of the casing pipe, thereby closing annuli, fractures and other voids outside the casing, while placing the cement there under compression. Kupresan et al. [74, 75] tested this method in three laboratory experiments on composite samples consisting of two concentric steel cylinders (length $60 \mathrm{~cm}$, diameter inner pipe $\sim 6 \mathrm{~cm}$, diameter outer pipe $\sim 10.2 \mathrm{~cm}$ ), where cement was injected in the annular region between these two pipes. After curing, sealing was poor due to the induction/presence of debonding defects at the inner pipe wall, producing apparent sample permeabilities of $1.4 \times 10^{-13}-7.1 \times 10^{-12} \mathrm{~m}^{2}$. Subsequent expansion of the inner pipe, by $2-8 \%$ via internal pressurisation or swaging, caused significant reduction in permeability, reducing this to $\sim 3 \times 10^{-19} \mathrm{~m}^{2}$ in the initially most permeable sample and to values below detection in the other two samples [74, 75]. These findings are promising, especially since increased confinement may help maintain the mechanical stability of the cement, i.e. by promoting permanent cohesive compaction as opposed to fracture [129].

A potential limitation to the method proposed by Kupresan et al. [74, 75], is that the casing diameter must be plastically expanded. In their experiments, this was achieved using (ductile) expandable casing tube technology [18, 88], swaged open with a pull-through mandrel and internal expansion cones. While expandable steel casings can be used in both new and existing wells, and have been applied effectively in remedial operations targeting punctured casings [6], it remains a relatively new technology [32]. This means that both legacy and presently operating wells, i.e. wells requiring abandonment in the coming decades, are generally furnished with conventional casing strings. This raises the question of whether or not the casing expansion concept can be applied, perhaps in modified form, to traditional casings. In such cases, the maximum attainable expansion ratios would necessarily be low $(<2 \%)$, since generally less ductile types of steel have been employed to date [56] than now appearing. However, even this limited expansion could still be effective, particularly in remedying leakage of $\mathrm{CO}_{2}$-bearing fluids. For $\mathrm{CO}_{2}$-rich fluids, it may be sufficient to reduce the aperture of fractures and debonding defects only to the point where reactive transport leads to self-sealing behaviour $[17,20,53,130]$, rather than completely closing interfacial flaws by purely mechanical means. Yet, it would not be trivial to expand conventional casing strings by even 1-2\% using the pull-through mandrel methods that are now being applied to expandable wellbore casing tubes. These approaches require the pipe wall to be smooth and of uniform thickness [18], while the wall thickness of conventional casing is rather poorly controlled, with specifications allowing for $12.5 \%$ variability [56]. Alongside mineral scaling, present in many existing wellbores $[34,62]$, significant lubrication issues are therefore expected [30], which in turn could cause swaging to induce considerable damage to the casing tube [18]. Given these difficulties, alternative approaches are needed for expanding conventional wellbore casings to seal leakage pathways outside of the casing in existing wellbores, e.g. during wellbore abandonment procedures.

Chemical reactions that involve a solid volume increase and produce a force of crystallisation (FoC) $[38,110,126]$, such as the hydration of $\mathrm{CaO}$ [21], offer obvious potential as agents causing expansion, and already find use in controlled, non-explosive demolition of building infrastructure [48]. These reactions are thermodynamically capable of 
producing very large mechanical stresses [67, 94, 119]. For the case of $\mathrm{CaO}$ hydration, thermodynamic models $[67,68]$, taking Gibbs energy of reaction and solid volume change data representative for downhole temperatures [82], predict FoC-induced stresses of up to $\sim 3.4 \mathrm{GPa}$. By comparison, preliminary calculations using Barlow's formula for the expansion of a cylindrical metal tube [7, 124], plus typical casing tube dimensions and plastic yield data for conventional casing steels [56], suggest that expanding conventional wellbore casing via internal pressurisation would require effective internal stresses in the range of 100-300 MPa. Constraints from casing burst studies provide similar values [39, 64]. As such, the stresses that could potentially be induced, if a wellbore would be plugged with low-porosity $\mathrm{CaO}$ aggregate, are more than sufficient to bring about casing expansion leading to mechanical closure of annuli and fractures similar to that seen in the experiments of Kupresan et al. [74, 75]. However, whether these theoretical FoC stresses can be attained in practice depends on whether reaction can go to completion, and hence on the reaction kinetics, the supply of reactants, the reaction mechanism, and the effect of stress on reaction. Moreover, at least some degree of control on the strains that develop upon $\mathrm{CaO}$ hydration would be required, to avoid excessive expansions that otherwise may lead to casing rupture.

Successful application of $\mathrm{CaO}$ hydration-induced FoC development in the expansion of wellbore casing would require a thorough, quantitative understanding of (a) the reaction mechanism controlling $\mathrm{CaO}$ hydration, (b) the deformation and fluid transport processes controlling stress and strain evolution and (c) whether the hydration process can be sufficiently regulated. In this study, we take a first step in this regard, by directly measuring the force of crystallisation generated during $\mathrm{CaO}$ hydration. Our results show FoC-induced stresses of up to $153 \mathrm{MPa}$. We discuss the reasons for the shortfall compared with thermodynamic theory and provide some suggestions for finding engineering solutions that may allow larger hydration-induced stresses and strains to be achieved in wellbore sealing operations in future.

\section{Background information}

Before presenting and analysing our experiments, we first introduce the basic concept of force of crystallisation, and briefly summarise previous experimental measurements and thermodynamic models addressing the phenomenon. We go on to derive our own thermodynamic model, establishing a framework in which to consider $\mathrm{CaO}$ hydration in our experiments.

\subsection{Force of crystallisation: examples and previous measurements}

Consider a fluid-mediated chemical reaction that involves dissolution of the reacting solid phases and precipitation of solid products from a supersaturated solution. When such a reaction involves an increase in solid volume and proceeds in a confined space, this can lead to development of a socalled force of crystallisation (FoC) [9, 22, 38, 105, $114,126]$. In other words, reaction can result in stress being exerted on the confining boundaries of the system. In principle, any thermodynamic driving force that can produce a supersaturation with respect to the solid product phase can generate a $\mathrm{FoC}$, as long as precipitation can occur under confined conditions, e.g. within load-bearing grain contacts [10, 103]. Well-known examples of such reactions include salt damage [24, 106], where supersaturation is achieved via evaporation and surface curvature effects [108, 110, 111], and a wide range of mineral reactions where the solid products comprise a larger volume than the solid reactants. Frost heave [24, 49, 115], where crystallisation is driven by a temperature-related phase change (cf. [114]), is a similar process. Examples of mineral reactions that have been shown or are believed to produce a FoC include (a) uptake of crystallisation water by thenardite to produce mirabilite $[35,118]$, (b) delayed ettringite formation in concrete $[37,54,116]$, (c) serpentinisation and possibly carbonation of peridotite [60, 67, 68, 97, 104], (d) replacement of leucite by analcime in low-silica rocks [61], (e) conversion of anhydrite into gypsum [70] and (f) the hydration of metal oxides such as quicklime $(\mathrm{CaO})$ and periclase $(\mathrm{MgO})[43,94]$. In a geological context, development of a force of crystallisation is widely considered to play an important role in pseudomorphic replacement [40, 89], as well as vein formation [40, 47, 87, 114] and reaction-driven fracturing [61, 97, 100, 104].

Despite this previous work on FoC-related processes, relatively few studies have been conducted where the magnitude of the FoC is determined directly. Becker and Day [9] attempted FoC measurement via the placement of dead weights on crystals growing from supersaturated solutions, created by gradual evaporation or cooling. They found that centimetre-sized crystals of alum, growing between glass plates, continued to grow and could raise a weight of $1 \mathrm{~kg}$ through distances of several hundreds of micrometres, and reported similar findings for copper sulphate, lead nitrate and potassium ferrocyanide. On the lower surface of the crystals, precipitation of new material was restricted to the periphery, producing a hopper-like morphology (see also [103]), preventing accurate determination of load-supporting area and hence stress corresponding to the FoC. The presence of unloaded crystals in 
the same solution was found to inhibit growth of the loaded crystal surfaces [10, 16, 114]. Performing similar experiments with improved resolution in displacement, Correns and Steinborn [23] and Correns [22] collected extensive data and demonstrated that the ability of alum crystals to lift a dead weight depended not only on the supersaturation, but also on which crystallographic plane was the loaded surface (see [38] for a recent commentary on these experiments). Khaimov-Mal'kov [71] repeated many of the earlier experiments on alum and reported crystal growth against a stress of $20 \mathrm{~kg} \mathrm{~cm}^{-2}(\sim 1.96 \mathrm{MPa})$ at $20 \%$ supersaturation. Also using a dead weight approach, Keulen et al. [70] reported hydration of anhydrite to form gypsum, causing expansion against stresses of up to $\sim 11 \mathrm{MPa}$. However, by far the largest stresses measured to date, at least to our knowledge, have been observed during $\mathrm{CaO}$ and $\mathrm{MgO}$ hydration. In experiments reported by Ostapenko [94], MgO samples were tightly confined in steel cylinders and subsequently hydrated, causing the sample to expand. This resulted in bulging or rupturing of the cylinders. The FoC that developed was estimated on the basis of the strength of the steel, by performing tests using cylinders of different wall thickness. The FoC-related stress estimates obtained ranged from 20 to $200 \mathrm{MPa}$. Similarly, using high-pressure expansion cells, Ghofrani and Plack [43] found that swelling cements based on $\mathrm{CaO}$ and $\mathrm{MgO}$ additives expand effectively against hydrostatic pressures up to $120 \mathrm{MPa}$.

\subsection{Thermodynamic models}

\subsubsection{Previous work}

The first steps towards a thermodynamic treatment of the force of crystallisation were made by Correns and Steinborn [23]. Based on chemical potential and energy balance arguments, they derived an expression for maximum stress generated as a function of supersaturation of the solution phase $(S)$, represented by $S=c / c_{\mathrm{s}}$, with $c$ and $c_{\mathrm{s}}$ solute concentrations in the supersaturated and a saturated solution, respectively. The result obtained was:

$\sigma_{\text {eff }}=\frac{R T}{V_{\mathrm{m}}} \ln (S)$

where $\sigma_{\text {eff }}=\sigma_{\mathrm{n}}-P$ is the maximum effective stress generated due to crystallisation, $P$ is the fluid pressure, $\sigma_{\mathrm{n}}$ is the normal stress on the loaded surface of the growing crystal, $R$ is the gas constant, $T$ is the absolute temperature, and $V_{\mathrm{m}}$ is the molar volume of the precipitating solid phase. Correns and Steinborn [23] further stated that, for a stressed crystal to continue to grow, there must exist a solution phase that separates the loaded crystal face from its constraint, as otherwise deposition of matter and growth in the load-bearing interface would be impossible (cf. [22, 105].

Several thermodynamic treatments and models have subsequently been published [36, 72, 105, 106, 126]. The models differ mainly in how the supersaturation $(S)$ is defined, e.g. in terms of solute activities, ion activity products, or in terms of the surface curvature of neighbouring crystals. Steiger [110, 111] reviewed these thermodynamic models and provided a comprehensive analysis, deriving an equation for the FoC based on chemical potentials of stressed and unstressed crystal faces, demonstrating the equivalence of the previous expressions, and considering effects of non-ideal behaviour of the solution phase.

The thermodynamic models discussed above consider direct precipitation from a (typically stoichiometrically) supersaturated solution, as investigated in the bulk of quantitative experimental studies to date (Sect. 2.1). Though without explicitly stating the steps involved, a number of studies [67, 68, 94] have generalised these models to include more complex chemical reactions, obtaining the result

$\sigma_{\text {eff }}=-\frac{\Delta G_{\mathrm{r}}}{\Delta V_{\mathrm{s}}}$

where $\Delta G_{\mathrm{r}}$ is the Gibbs energy change of reaction and $\Delta V_{\mathrm{s}}$ denotes the solid volume change associated with the reaction per mole (cf. Eqn. E5 of Kelemen and Hirth [67]). To our knowledge, these models have not been experimentally verified.

\subsubsection{Model for FoC development and application to $\mathrm{CaO}$ hydration}

We will now explicitly derive a similar expression to Eq. 2 and subsequently apply the result to $\mathrm{CaO}$ hydration, which is the target of our experiments. Throughout, we adopt the convention that compressive stresses and volume expansions are represented positive. In deriving the model, it is assumed that reaction will not be inhibited by clogging of transport pathways, by sealing of grain boundaries, or by stress-driven expulsion of the solution phase from grain boundaries. In other words, it is assumed that a solution phase remains present in the loaded interfaces (cf. $[22,105])$. This may, for instance, be in the form of thin films or microscale channels, observed to occur during stress-driven dissolution or pressure solution [28, 29, 120, 121]. The initial solid $(\mathrm{CaO}$ powder in our experiments) will be considered to consist of a single, pure phase. Reaction will be treated as a replacement process, i.e. with solid products and reactants in contact across fluid-filled grain boundaries and therefore experiencing the 
same stress. The aqueous solution phase present in the open pores is assumed to be well mixed and to exist at a reference pressure $(P)$ and temperature $(T)$. Prior to any reaction, the initial solid phase is assumed to be in mechanical and thermal equilibrium with this solution phase, i.e. also characterised by a hydrostatic stress state of magnitude $P$ and temperature $T$. In addition, we assume that reaction occurs under isothermal conditions and that no other dissipative processes operate in the system.

Under hydrostatic reference conditions $(P, T)$, the Gibbs free energy change of reaction (i.e. the thermodynamic driving force) for any given reaction involving $I$ solid phases and $J$ components in the solution phase can be written as

$\Delta_{\mathrm{r}} G^{P T}=\sum_{i=1}^{I} v_{i} \mu_{i}^{P T}+\sum_{j=1}^{J} v_{j} \mu_{j}^{P T}$

Here, $v$ are stoichiometric coefficients for the $I$ solid phases and $J$ components in the solution phase participating in reaction, while $\mu^{P T}$ are the chemical potentials of these components in the hydrostatic reference state $(P, T)$. Of course, $v$ is positive for reaction products and negative for reactants.

If the growth of the solid products is restricted by a zero or limited displacement boundary condition, then reaction will lead to the build-up of a normal stress $(\sigma)$ at the interfaces of the product and reactant grains. Assuming drained conditions, i.e. that the fluid phase remains at the initial pressure $P$, ongoing reaction in the stressed state will be associated with the free energy change (cf. Eq. 3)

$\Delta_{\mathrm{r}} G^{\sigma T}=\sum_{i=1}^{I} v_{i} \mu_{i}^{\sigma T}+\sum_{j=1}^{J} v_{j} \mu_{j}^{(\sigma) P T}$

Here, $\mu_{i}^{\sigma T}$ are chemical potentials of the solid phases at stress $\sigma$ and temperature $T$, while $\mu_{j}^{(\sigma) P T}$ are the chemical potentials of the components present in the solution phase, which in general will be different compared with the initial $(P, T)$ conditions, due to changes in their concentration in the stressed state.

As constricted reaction proceeds, the stress experienced by the solid phases will continue to increase, until the stressed solids are in equilibrium with the components present in the solution phase, i.e. until $\Delta_{\mathrm{r}} G^{\sigma T}=0$. Putting this into Eq. 4 and making use of Eq. 3, the change in total free energy of the solid phases in the stressed state $(\sigma, T)$ compared with the reference state $(P, T)$ can be written as

$\sum_{i=1}^{I} v_{i}\left(\mu_{i}^{\sigma T}-\mu_{i}^{P T}\right)=-\Delta_{\mathrm{r}} G^{P T}-\sum_{j=1}^{J} v_{j}\left(\mu_{j}^{(\sigma) P T}-\mu_{j}^{P T}\right)$

For solid phases, the chemical potential is a surface property [44], which from thermodynamic treatments of stressed solids [27, 44, 65, 66, 78, 79, 86, 95] can be related to the normal stress $(\sigma)$ acting on the crystal surface via:

$\mu_{i}^{\sigma T} \approx f_{i}^{\sigma T}+\sigma V_{\mathrm{m}, i}^{\sigma T}$

Here, $f_{i}^{\sigma T}$ and $V_{\mathrm{m}, i}^{\sigma T}$ denote the molar Helmholtz free energy and molar volume of solid $i$ in the stressed state (e.g. [78]). For the hydrostatic reference conditions $(P, T)$, we have $\mu_{i}^{P T}=f_{i}^{P T}+P V_{\mathrm{m}, i}^{P T}$. Considering elastic strain of the solids and assuming the normal stress on the solids $(\sigma)$ to be isotropic, the molar volume of the solid in the stressed state $(\sigma, T)$ can be written in terms of the molar volume of the solid under hydrostatic conditions $(P, T)$, yielding

$V_{\mathrm{m}, i}^{\sigma T}=V_{\mathrm{m}, i}^{P T}+\Delta V_{\mathrm{m}, i} \quad$ with $\quad \Delta V_{\mathrm{m}, i}=-\frac{V_{\mathrm{m}, i}^{P T}}{B_{i}}(\sigma-P)$

where $\Delta V_{\mathrm{m}, i}$ is the difference in molar volume between the stressed and unstressed solid, and $B_{i}$ is the bulk modulus of the solid. The energy associated with elastic strain of the stressed solid contributes to its molar Helmholtz free energy, for which we may correspondingly write

$f_{i}^{\sigma T}=f_{i}^{P T}+\Delta f_{i} \quad$ with $\quad \Delta f_{i}=-\frac{\sigma V_{\mathrm{m}, i}^{P} e_{\mathrm{V}}}{2}=-\frac{\sigma \Delta V_{\mathrm{m}, i}}{2}$

where $\Delta f_{i}$ is the difference in molar Helmholtz free energy between the stressed and unstressed solid, and $e_{\mathrm{V}}$ is the volumetric strain associated with application of isotropic stress $\sigma$. Equations 5, 6, 7 and 8 can be combined to obtain

$$
\begin{aligned}
(\sigma & -P) \sum_{i=1}^{I} v_{i}\left(1-\frac{\sigma}{2 B_{i}}\right) V_{\mathrm{m}, i}^{P T}=-\Delta_{\mathrm{r}} G^{P T} \\
& -\sum_{j=1}^{J} v_{j}\left(\mu_{j}^{(\sigma) P T}-\mu_{j}^{P T}\right)
\end{aligned}
$$

For FoC-induced stresses of up to a few GPa, the terms $\sigma /$ $\left(2 B_{i}\right)$ will be small (given typical bulk moduli in the range of 10-100s of GPa). As such, it is easily shown that small differences in elastic strain between the stressed and unstressed solids may be neglected. Taking $f_{i}^{\sigma T} \approx f_{i}^{P T}$ and $V_{\mathrm{m}, i}^{\sigma T} \approx V_{\mathrm{m}, i}^{P T}$, Eq. 9 simplifies to

$$
\begin{aligned}
\sigma_{\mathrm{eff}} & =\sigma-P \\
& =-\frac{1}{\sum v_{i} V_{\mathrm{m}, i}^{P T}}\left[\Delta_{r} G^{P T}+\sum v_{j}\left(\mu_{j}^{(\sigma) P T}-\mu_{j}^{P T}\right)\right]
\end{aligned}
$$

This gives the maximum effective normal stress that can develop due to precipitation of a confined solid product phase, i.e. the stress attained at equilibrium or the stress required to remove the driving force for further reaction. Note that Eq. 10 corresponds to Eq. 2 only if reactioninduced changes in the chemical potentials of the components present in the solution phase can be neglected, which 
in general is by no means clear, for example, when considering complex chemical reactions.

Let us now apply Eq. 10 to the specific case of $\mathrm{CaO}$ hydration. When $\mathrm{CaO}$ is exposed to water, this will lead to the formation of $\mathrm{Ca}(\mathrm{OH})_{2}$ (portlandite). Two different reaction mechanisms have been reported for this hydration, namely (a) "vapour phase hydration", which occurs via a pseudomorphic, topotactic, solid-state transformation involving an intermediate, disordered $\mathrm{Ca}(\mathrm{OH})_{2}$ phase $[11,45,73]$, and (b) so-called "through-solution" or "wet hydration". For this second mechanism, it is at present unclear whether (a) the $\mathrm{CaO}$ first dissolves in the solution phase (water) and subsequently precipitates as $\mathrm{Ca}(\mathrm{OH})_{2}$ $[12,84,101,128]$, or (b) direct conversion of $\mathrm{CaO}$ into $\mathrm{Ca}(\mathrm{OH})_{2}$ occurs, as in vapour phase hydration, followed by (partial) dissolution (and re-precipitation) of the $\mathrm{Ca}(\mathrm{OH})_{2}$ formed $[12,113]$.

In the confined experiments reported here, "wet hydration" is considered the most likely mechanism, at least initially, as reaction was initiated by vacuum-flushing liquid water into the sample chamber. Assuming a stoichiometrically balanced chemical reaction (as expressed in Eqs. 3 and 10), we now have to consider the two possible reaction pathways for the wet hydration process discussed above. If this process involves a true dissolution-precipitation mechanism (e.g. [101]), and we allow for complete reaction being prevented by stress build-up, then we must have

$$
\begin{aligned}
& \mathrm{CaO}_{(\mathrm{s})}+\mathrm{H}_{2} \mathrm{O}_{(\mathrm{l})} \Rightarrow \mathrm{Ca}_{(\mathrm{aq})}^{2+}+2 \mathrm{OH}_{(\mathrm{aq})}^{-} \text {and } \\
& \alpha \mathrm{Ca}_{(\mathrm{aq})}^{2+}+2 \alpha \mathrm{OH}_{(\mathrm{aq})}^{-} \Leftrightarrow \alpha \mathrm{Ca}(\mathrm{OH})_{2(\mathrm{~s})}, \text { which on adding yield } \\
& \mathrm{CaO}_{(\mathrm{s})}+\mathrm{H}_{2} \mathrm{O}_{(\mathrm{l})} \Rightarrow \alpha \mathrm{Ca}(\mathrm{OH})_{2(\mathrm{~s})}+(1-\alpha) \mathrm{Ca}_{(\mathrm{aq})}^{2+} \\
& \quad+2(1-\alpha) \mathrm{OH}_{(\mathrm{aq})}^{-}
\end{aligned}
$$

where per mole of $\mathrm{CaO}$ that dissolves $\alpha$ moles of $\mathrm{Ca}(\mathrm{OH})_{2}$ precipitate, with $\alpha \leq 1$. Alternatively, if wet hydration would involve direct transformation of $\mathrm{CaO}$ into $\mathrm{Ca}(\mathrm{OH})_{2}$ (e.g. [113]), then we must have

$$
\begin{aligned}
& \mathrm{CaO}_{(\mathrm{s})}+\mathrm{H}_{2} \mathrm{O}_{(\mathrm{l})} \Rightarrow \mathrm{Ca}(\mathrm{OH})_{2(\mathrm{~s})} \text { and } \\
& (1-\alpha) \mathrm{Ca}(\mathrm{OH})_{2(\mathrm{~s})} \Leftrightarrow(1-\alpha) \mathrm{Ca}_{(\mathrm{aq})}^{2+}+(1-\alpha) \mathrm{OH}_{(\mathrm{aq})}^{-},
\end{aligned}
$$

which on adding yield

$$
\begin{aligned}
& \mathrm{CaO}_{(\mathrm{s})}+\mathrm{H}_{2} \mathrm{O}_{(\mathrm{l})} \Rightarrow \alpha \mathrm{Ca}(\mathrm{OH})_{2(\mathrm{~s})}+(1-\alpha) \mathrm{Ca}_{(\mathrm{aq})}^{2+} \\
& \quad+2(1-\alpha) \mathrm{OH}_{(\mathrm{aq})}^{-}
\end{aligned}
$$

where per mole of $\mathrm{CaO}$ that converts $(1-\alpha)$ moles of the $\mathrm{Ca}(\mathrm{OH})_{2}$ formed subsequently dissolves again with $\alpha \leq 1$. Note that Eqs. 11a and $11 \mathrm{~b}$ yield the same net reaction, regardless of the specific pathway. The value of $\alpha$ will depend on various system properties, such as the fluid composition and the effective fluid-to-solid ratio. Considering the overall transfer of mass that is involved in attaining equilibrium, i.e. in going from the initial, hydrostatic reference state $(P, T)$ to the stressed equilibrium state $(\sigma, T)$, the final equilibrium state must be such that the $\mathrm{Ca}^{2+}$ and $\mathrm{OH}^{-}$concentrations in the fluid (or, rather, their chemical activities) are in equilibrium with the solids, so that at least some dissolved material remains in solution, with $\alpha<1$. However, given the low solubility of $\mathrm{Ca}(\mathrm{OH})_{2}$ [31], combined with low fluid-to-rock ratios characterising the experiments reported here, we expect that taking $\alpha \approx 1$ will not introduce significant error. In other words, the mass of calcium hydroxide stored in the solution phase will be negligible compared with that precipitated. Making the assumption $\alpha \approx 1$, Eq. 11 simplifies to

$\mathrm{CaO}_{(s)}+\mathrm{H}_{2} \mathrm{O}_{(l)} \Rightarrow \mathrm{Ca}(\mathrm{OH})_{2(s)}$

and, in turn, means that Eq. 10 can be simplified and rewritten as

$\sigma_{\mathrm{eff}}=\frac{\Delta_{\mathrm{f}} G_{\mathrm{CaO}}^{P T}+\Delta_{\mathrm{f}} G_{\mathrm{H}_{2} \mathrm{O}}^{P T}-\Delta_{\mathrm{f}} G_{\mathrm{Ca}(\mathrm{OH})_{2}}^{P T}}{V_{\mathrm{m}, \mathrm{Ca}(\mathrm{OH})_{2}}^{P T}-V_{\mathrm{m}, \mathrm{CaO}}^{P T}}$

where $\Delta_{\mathrm{r}} G^{P T}$ is now expressed in terms of the Gibbs energies of formation $\left(\Delta_{\mathrm{f}} G^{P T}\right)$ of the subscripted chemical species at the reference $P, T$ conditions. This result is essentially equivalent to Eq. 2 (cf. Eqn. E5 of Kelemen and Hirth [67]). However, note that it rests on the assumption that $\alpha=1$, i.e. it neglects compositional change in the solution phase, as well as neglecting stress-induced changes in $f_{i}$ and $V_{\mathrm{m}, i}$.

The standard molar thermodynamic properties of the chemical species involved (i.e. in Eq. 12) can be found for $P=0.1 \mathrm{MPa}(1 \mathrm{bar})$ and $T=298.15 \mathrm{~K}\left(25^{\circ} \mathrm{C}\right)$ in the papers by Matschei et al. [85] and Lothenbach et al. [82], and are listed in Table 1. Following Lothenbach et al. [82], the corresponding values at $65{ }^{\circ} \mathrm{C}$ were calculated using [2]

$$
\begin{aligned}
& \Delta_{\mathrm{f}} G^{T}=\Delta_{\mathrm{f}} G_{T_{0}}^{\bigcirc}-S_{T_{0}}^{\bigcirc}\left(T-T_{0}\right)-\beta_{0}\left(T \ln \frac{T}{T_{0}}-T+T_{0}\right) \\
& -\beta_{1} \frac{\left(T-T_{0}\right)^{2}}{2}-\beta_{2} \frac{\left(T-T_{0}\right)^{2}}{2 T T_{0}^{2}}-\beta_{3} \frac{2\left(\sqrt{T}-\sqrt{T_{0}}\right)^{2}}{\sqrt{T_{0}}}
\end{aligned}
$$

where $T_{0}$ is the reference (standard) temperature $(298.15 \mathrm{~K})$ and $\beta_{x}(x=0,1,2,3)$ are the empirical coefficients of a heat capacity equation of the form $C_{P}(T)=\beta_{0}+\beta_{1} T+\beta_{2} T^{-2}+\beta_{3} T^{-0.5}$.

Using Eq. 13 with the thermodynamic data in Table 1, it is straightforward to calculate the maximum stress that can develop at the surface of a confined crystal of portlandite $\left[\mathrm{Ca}(\mathrm{OH})_{2}\right]$ growing as a result of $\mathrm{CaO}$ hydration under initial conditions $(P, T)$. Doing so for reaction at $65^{\circ} \mathrm{C}$ and atmospheric fluid pressure yields a value of $\sim 3.4 \mathrm{GPa}$. 
Table 1 Standard molar thermodynamic properties of water, $\mathrm{CaO}$ and $\mathrm{Ca}(\mathrm{OH})_{2}$ at $298.15 \mathrm{~K}$ and $0.1 \mathrm{MPa}$. Data from Matschei et al. [85]

\begin{tabular}{llll}
\hline Property & $\mathrm{CaO}$ & $\mathrm{Ca}(\mathrm{OH})_{2}$ & $\mathrm{H}_{2} \mathrm{O}$ \\
\hline$\Delta_{\mathrm{f}} G_{T_{0}}^{\bigcirc}\left(\mathrm{kJ} \mathrm{mol}^{-1}\right)$ & -604.0 & -897.0 & -237.2 \\
$\Delta_{\mathrm{f}} H_{T_{0}}^{\bigcirc}\left(\mathrm{kJ} \mathrm{mol}^{-1}\right)$ & -635 & -985 & -286 \\
$S_{T_{0}}\left(\mathrm{~J} \mathrm{~K}^{-1} \mathrm{~mol}^{-1}\right)$ & 39 & 83 & 70 \\
$V_{\mathrm{m}}^{0}\left(\mathrm{~cm}^{3} \mathrm{~mol}^{-1}\right)$ & 17 & 33 & 18 \\
$\beta_{0}\left(\mathrm{~J} \mathrm{~K}^{-1} \mathrm{~mol}^{-1}\right)$ & 49 & 187 & 75 \\
$\beta_{1}\left(\mathrm{~J} \mathrm{~K}^{-2} \mathrm{~mol}^{-1}\right)$ & 0.004 & -0.022 & 0 \\
$\beta_{2}\left(\mathrm{~J} \mathrm{~K} \mathrm{~mol}^{-1}\right)$ & $-6.53 \times 10^{5}$ & 0 & 0 \\
$\beta_{3}\left(\mathrm{~J} \mathrm{~K}^{-0.5} \mathrm{~mol}^{-1}\right)$ & 0 & -1600 & 0 \\
\hline
\end{tabular}

\section{Experimental methods}

To measure the force of crystallisation that is generated during $\mathrm{CaO}$ hydration, we performed compaction/expansion experiments on $\mathrm{CaO}$ powder at a temperature of $65{ }^{\circ} \mathrm{C}$, representative for shallow crustal reservoirs, using a uniaxial deformation (oedometer-type) set-up located in an Instron loading frame. After dry precompaction, the sample assembly containing the $\mathrm{CaO}$ aggregate was flooded with water, initiating the hydration reaction. Three types of experiments were performed, namely (a) position-control experiments, in which the Instron position was fixed so as to restrict sample expansion as much as possible, thus allowing a force of crystallisation to develop, (b) load-limit experiments, in which the Instron was programmed to initially maintain a fixed position, but switch to load-control mode once the FoC-induced axial stress attained a preset threshold value and (c) constant-load experiments, where the Instron load was fixed, allowing measurement of $\mathrm{CaO}$ hydration-induced expansion against a constant axial force (and hence stress). A complete list of the experiments performed, together with key experimental data, is given in Table 2.

\subsection{Sample material and assembly}

The $\mathrm{CaO}$ powder used in this study was prepared from Carrara marble (high-purity $\mathrm{CaCO}_{3}$ ), which for this purpose was crushed and sieved to a grain size of 90-150 $\mu \mathrm{m}$. Prior to each experiment, a batch of marble powder was calcined at $1100{ }^{\circ} \mathrm{C}$ for $\sim 16 \mathrm{~h}$. The calcined powder was retrieved after allowing the furnace to cool to $\sim 350{ }^{\circ} \mathrm{C}$. After thorough mixing and disaggregation of the $\mathrm{CaO}$ powder obtained, some $120-360 \mathrm{mg}$ was located in the sample assembly, depending on desired sample thickness. This assembly consisted of a small compaction die furnished with upper and lower loading pistons (outer diameter $19.8 \mathrm{~mm}$, bore diameter $9.8 \mathrm{~mm}$-Fig. 1a), all constructed from Monel K-500, a corrosion resistant nickel-copper alloy. The top piston of the assembly contained a central bore and was tipped with a stainless steel

Table 2 Summary of the experiments performed

\begin{tabular}{llllllllll}
\hline Test no. & $m_{0}(\mathrm{mg})$ & $L_{0}(\mathrm{~mm})$ & $\phi_{0}(\%)$ & $\sigma_{0}(\mathrm{MPa})$ & $\sigma_{T H}(\mathrm{MPa})$ & $\sigma_{5 \mathrm{~h}}(\mathrm{MPa})$ & $\Delta L_{5 \mathrm{~h}}(\mathrm{~mm})$ & $\sigma_{\max }(\mathrm{MPa})$ & $\Delta L_{\max }(\mathrm{mm})$ \\
\hline A01PC & 355.8 & 2.19 & 35.4 & $\sim 1.3$ & 250 & 128.0 & 0.242 & 133.8 & 0.247 \\
A02PC & 355.1 & 2.18 & 35.3 & $\sim 1.3$ & 250 & 132.9 & 0.245 & 138.2 & 0.248 \\
A03PC & 176.9 & 1.11 & 36.8 & $\sim 1.3$ & 250 & 94.1 & 0.205 & 95.5 & 0.206 \\
A04PC & 177.3 & 1.11 & 36.8 & $\sim 1.3$ & 250 & 97.1 & 0.212 & 98.2 & 96.4 \\
A05PC & 124.8 & 0.70 & 29.0 & $\sim 1.3$ & 250 & 92.9 & 0.196 & 151.4 & 0.104 \\
A06PC & 124.9 & 0.68 & 27.4 & 60 & 250 & 141.6 & 0.096 & 152.5 \\
A07PC & 121.2 & 0.69 & 30.4 & 120 & 250 & 146.0 & 0.035 & 0.039 \\
A08PC & 353.4 & 2.34 & 40.0 & 90 & 250 & 131.3 & 0.057 & 135.6 & 0.060 \\
A09TH & 347.5 & 2.14 & 35.6 & $\sim 1.3$ & 30 & TH-30 & 0.609 & TH-30 & 0.611 \\
A10TH & 351.7 & 2.09 & 33.1 & $\sim 1.3$ & 60 & TH-60 & 0.288 & TH-60 & 0.435 \\
A11CL & 123.8 & 0.65 & 24.9 & 60 & CL-60 & CL-60 & 0.111 & CL-60 & 0.156 \\
A12CL & 123.1 & 0.66 & 25.7 & 120 & CL-120 & CL-120 & 0.023 & CL-120 & 0.030 \\
A13CL & 120.8 & 0.71 & 32.1 & 225 & CL-225 & CL-225 & -0.043 & - & - \\
A14CL & 352.7 & 2.10 & 33.3 & 225 & CL-225 & CL-225 & -0.042 & - \\
\hline
\end{tabular}

PC, Instron position-controlled experiment; TH, transfer-and-hold experiment: transfer-load attained and Instron operation switched to constantload mode at $\sigma=\sigma_{\mathrm{TH}} ; \mathrm{CL}$, constant-load mode experiment: Instron at $\sigma=\sigma_{0}$ throughout test. Symbols: $m_{0}=$ initial sample mass, $L_{0}=$ initial sample length, $\phi_{0}=$ initial sample porosity, $\sigma_{0}=$ initial axial stress applied to the sample, $\sigma_{\mathrm{TH}}=$ stress limit where Instron loading frame will transfer from fixed-position mode to constant-load mode, $\sigma_{5 \mathrm{~h}}=$ axial stress after $5 \mathrm{~h}, \Delta L_{5 \mathrm{~h}}=$ axial displacement after $5 \mathrm{~h}, \sigma_{\text {max }}=$ maximum axial stress, $\Delta L_{\max }=$ maximum axial displacement 


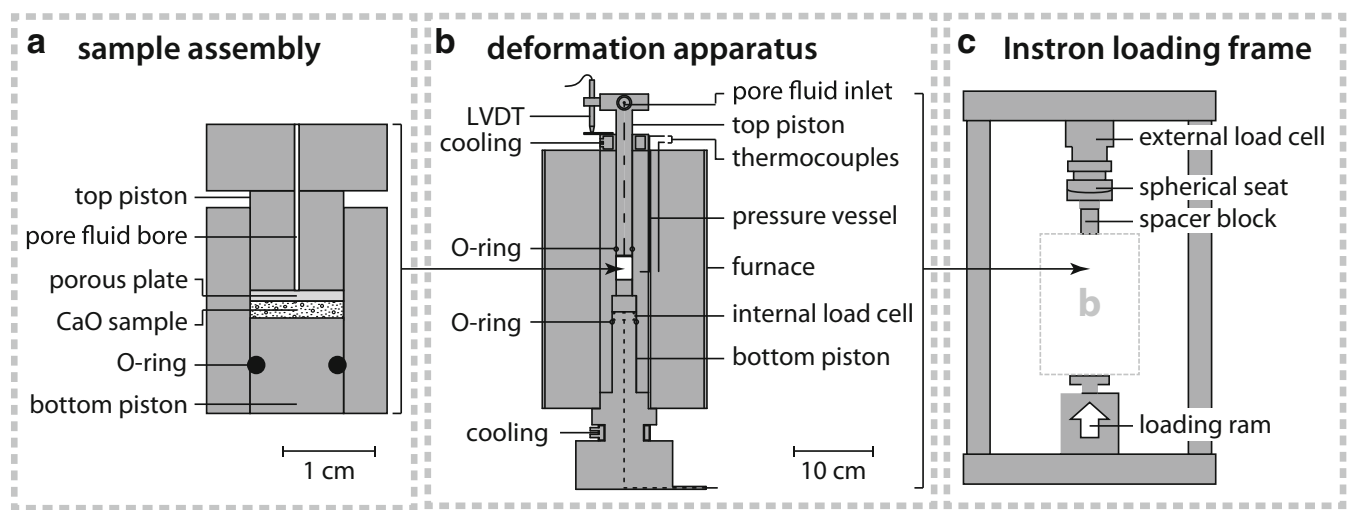

Fig. 1 Schematic of the sample assembly and uniaxial deformation apparatus, a sample assembly with $\mathrm{CaO}$ powder sample, b main uniaxial deformation vessel and $\mathbf{c}$ Instron loading frame. LVDT linear variable differential transformer

porous plate (Fig. 1a) to provide pore fluid access to the sample during the experiments. The bottom piston was solid. Note that before loading the sample into the sample assembly, the assembly was oven-dried overnight at $50{ }^{\circ} \mathrm{C}$.

\subsection{Experimental set-up}

The $\mathrm{CaO}$ hydration experiments were performed by placing the sample assembly/die into an externally heated, uniaxial compaction apparatus (Fig. 1b), applying load by means of an Instron 8862 servo-controlled testing machine (Fig. 1c)—see Schutjens [107] and Pluymakers et al. [98]. The compaction apparatus consists of a pressure vessel with a fixed bottom piston and movable top piston, constructed from Monel K-500. The diameter of the vessel bore and loading pistons are nominally $20 \mathrm{~mm}$, with the sample assembly described above fitting closely inside (Fig. 1a). Sealing of the loading piston in the main compaction vessel was achieved using Viton O-rings. Pore fluid was supplied to the sample assembly via a central bore in the top piston. The force applied to the sample assembly via the top piston was measured externally, using the Instron load cell (100 kN range, resolution $\pm 0.05 \mathrm{kN})$, while that supported by the bottom piston was measured using an internal load cell located in the bottom piston of the main compaction vessel $(100 \mathrm{kN}$ range, resolution $\pm 0.05 \mathrm{kN}$ ). Displacement of the main vessel piston relative to the main vessel was measured externally using a linear variable differential transformer (LVDT; range $\pm 1 \mathrm{~mm}$, resolution, $\pm 1 \mu \mathrm{m}$ ), mounted between the top piston and the top of the pressure vessel (Fig. 1b). Experiment temperature was regulated to within $\pm 0.5{ }^{\circ} \mathrm{C}$ using a K-type chromel-alumel thermocouple, located between the furnace windings, connected to a proportional-integralderivative controller. Sample temperature was measured using a second K-type thermocouple, embedded in the vessel wall close to the sample position.

\subsection{Testing procedure}

In each experiment, the $\mathrm{CaO}$-loaded sample assembly (Fig. 1a) was first precompacted outside the main compaction vessel for $1 \mathrm{~h}$ at $250 \mathrm{MPa}$ axial stress, under laboratory dry conditions. This was done by directly loading the sample assembly/die using only the Instron loading frame and produced disc-shaped $\mathrm{CaO}$ aggregates. The top piston of the sample assembly was then extracted to remove powder adhering to the piston and sample vessel bore. After returning the top piston, the sample assembly was weighed to determine the mass of $\mathrm{CaO}$ powder $\left(m_{0}-\right.$ Table 2) present in the sample assembly. The assembly was then carefully lowered into the main deformation apparatus, and the corresponding top piston was inserted until close to touch (Fig. 1b). This was done on the bench. Note this main top piston was dried overnight (at $50{ }^{\circ} \mathrm{C}$ ) prior to each experiment. The main vessel was then installed in the Instron loading frame (Fig. 1c), and the Instron loading ram advanced to apply and maintain a small, constant load of $0.1 \mathrm{kN}$, corresponding to $\sim 1.3 \mathrm{MPa}$ axial stress. The apparatus was then heated to $65{ }^{\circ} \mathrm{C}$ over the course of $\sim 3 \mathrm{~h}$, in load-control mode. After reaching a stable target temperature, the Instron ram was retracted in position-control mode, creating a $\sim 1$-mm gap between the loading frame and the top piston, to establish the zero-value of the external force signal. The original small load was then reapplied in load-control mode. The dry samples were then subjected to a second precompaction stage. This involved (a) loading the sample to an effective axial stress of $250 \mathrm{MPa}$, by increasing the applied force linearly over $5 \mathrm{~min}$, (b) maintaining this stress for $\sim 5 \mathrm{~min}$, and then (c) unloading to the initial load $(\sim 1.3 \mathrm{MPa})$, again over $5 \mathrm{~min}$. 
Following this second precompaction stage, the samples were placed under the desired initial effective stress $\left(\sigma_{\mathrm{a}, 0}\right)$, using a 5-min duration, linear load ramp, in experiments where $\sigma_{\mathrm{a}, 0}>1.3 \mathrm{MPa}$, establishing a corresponding initial, zero-displacement piston position at the chosen stress (note that in experiments A02PC, A03PC, A04PC and A09TH, this reference position was established without first performing the second precompaction stage). The thicknesses $\left(L_{0}\right)$ and porosities $\left(\phi_{0}\right)$ of the samples at this point are listed in Table 2.

From this point in the experiments, the testing procedure employed differed slightly between the three types of test. For the position-control (A01PC-A08PC) and load-limit experiments (A09TH, A10TH), operation of the Instron loading frame was transferred to position-control mode prior to the start of the experiment. However, the Instron loading frame was programmed such that the operation mode would switch from position-control back to loadcontrol once a specified load was attained. While merely a safety measure in the position-control experiments, this transfer in operation mode was actively employed in the load-limit experiments, by applying lower load limits, corresponding to an axial stress $\sigma_{T H}$ (Table 2). In the case of the load-control experiments (A11CL-A14CL), the Instron was operated in load-control mode from the start, maintaining the initial effective stress $\left(\sigma_{\mathrm{a}, 0}\right)$ throughout the hydration experiment.

In all three types of experiments, measurement was initiated by vacuum-flushing water into the upper piston plus sample assembly at $t=0$. To ensure the sample was saturated with water, the pore fluid system was briefly pressurised to $\sim 10 \mathrm{MPa}$, using a hand pump. This pressurised state lasted for a few tens of seconds before the pressure was released, maintaining an open connection to atmospheric (laboratory air) pressure throughout the remainder of the experiment. Upon experiment termination, the sample was unloaded fully. This was done by retracting the Instron loading ram to create a $\sim 1$-mm gap between it and the top piston of the deformation apparatus. Subsequently, the furnace was switched off and the deformation apparatus was allowed to cool for 1-2 h before retrieving the sample assembly.

\subsection{Data acquisition and processing}

During each experiment, the external and internal load, Instron position, local position (displacement between the upper piston and main vessel) and temperature were logged every second, using a 16-bit National Instruments data acquisition system and VI Logger software. Data processing yielded effective axial stress $\left(\sigma_{\mathrm{a}}\right)$ and axial strain $\left(e_{\mathrm{a}}\right)$. The effective axial stress was measured directly using the external load cell signal, as the fluid pressure was atmospheric. The displacement and strain data were corrected for distortion of the deformation apparatus and Instron loading frame using predetermined stiffness calibrations, obtained at experimental temperature. Note that the axial strain was defined in terms of the engineering strain $e_{\mathrm{a}}=\Delta L / L_{0}$, where $L_{0}$ denotes the reference (initial) thickness of the sample (Table 2), and $\Delta L$ represents the finite axial displacement associated with the expansion or compaction of the sample at a given moment, i.e. the thickness change of the sample, corrected for machine effects. The initial sample porosity $\left(\phi_{0}\right)$, i.e. that of the dry $\mathrm{CaO}$ aggregate, was estimated using $\phi_{0}=1-m_{0} /$ $\left(\rho_{\mathrm{CaO}} L_{0} A\right)$, where $m_{0}$ denotes sample mass, $\rho_{\mathrm{CaO}}$ is the density of pure $\mathrm{CaO}\left(3340 \mathrm{~kg} \mathrm{~m}^{-3}\right)$, and $A$ is the crosssectional area of the sample assembly bore $\left(7.543 \times 10^{-5} \mathrm{~m}^{2}\right.$-Fig. 1a). Sample porosity evolution after the addition of water $(\phi)$ could not be determined, as the experimental design did not allow for pore volume changes to be distinguished from hydration-induced changes in solid volume.

\subsection{Microstructural analysis}

After retrieving the sample assembly from the deformation apparatus, the top piston of the assembly was removed and the sample plus bottom piston were carefully pushed out to minimise sample disturbance. The samples were then dried in a furnace at $50{ }^{\circ} \mathrm{C}$ for $\sim 12 \mathrm{~h}$, and subsequently stored in individual containers. Selected samples were studied optically and using scanning electron microscopy (SEM). To obtain cross sections through the disc-shaped samples, these were broken axially using a razor blade and subsequently mounted on a SEM stub using carbon paint. In addition, samples of our $\mathrm{CaO}$ starting material (i.e. the calcination product of Carrara marble) were characterised by means of SEM, thermogravimetric analysis (TGA) and laser diffraction particle size distribution analysis.

\section{Results and analysis}

\subsection{Mechanical data}

In the following, compressive axial stresses and dilatant axial strains $\left(e_{\mathrm{a}}\right)$, i.e. sample expansion, are taken as positive. The maximum force of crystallisation was defined as the maximum axial stress $\left(\sigma_{\max }\right)$ measured while the sample showed a positive axial displacement $(\Delta L)$, i.e. net expansion, with $\Delta L_{\max }$ denoting the greatest axial expansion observed. In addition, the displacement and effective axial stress supported by the hydrating $\mathrm{CaO}$ samples at $t=5 \mathrm{~h}$ were also employed as measures for the force of 
crystallisation. The key mechanical data obtained in the experiments are summarised in Table 2.

\subsubsection{Constant-position experiments}

Figure $2 \mathrm{a}$, and $2 \mathrm{~b}$ shows effective axial stress and axial strain versus time data obtained from hydration experiments A01PC, A02PC, A03PC, A04PC and A05PC (Table 2). These tests were performed with the Instron loading frame in position-control mode, imposing an initial (effective) axial stress $\left(\sigma_{\mathrm{a}, 0}\right)$ of $\sim 1.3 \mathrm{MPa}$ and using an axial stress limit $\left(\sigma_{T H}\right)$ of $250 \mathrm{MPa}$. Note that A01PC, $\mathrm{A} 02 \mathrm{PC}, \mathrm{A} 03 \mathrm{PC}$ and A04PC were characterised by initial porosities ranging from 35.4 to $36.8 \%$, whereas $\mathrm{A} 05 \mathrm{PC}$ was precompacted slightly further, with $\phi_{0}=29.0 \%$. However, the main variable in this subset of experiments was initial sample thickness $\left(L_{0}\right)$, which varied from $2.18 \mathrm{~mm}$ in $\mathrm{A} 01 \mathrm{PC}$ and $\mathrm{A} 02 \mathrm{PC}$, to $1.11 \mathrm{~mm}$ in $\mathrm{A} 03 \mathrm{PC}$ and $\mathrm{A} 04 \mathrm{PC}$, and $0.7 \mathrm{~mm}$ in A05PC (Table 2). In all five experiments, vacuum-flushing of water into the $\mathrm{CaO}$ sample resulted in the rapid development of an axial stress, attaining values $>75 \mathrm{MPa}$ within 30 min (Fig. 2a). At $5 \mathrm{~h}$ of reaction, axial stresses ranged from $\sim 95 \mathrm{MPa}$ for samples of $L_{0}<1.2 \mathrm{~mm}$ (A03PC, A04PC and A05PC) to
$135 \mathrm{MPa}$ in experiments with $L_{0}=2.18 \mathrm{~mm}$ (A01PC and A02PC). The $\sigma_{\max }$ values also increased with increasing $L_{0}$ (Fig. 2a; Table 2). Conversely, the swelling strains $\left(e_{\mathrm{a}}\right)$ decreased with increasing initial sample thickness (Fig. 2b). Figure 2c shows axial stress versus axial expansion $(\Delta L)$ of the samples generated by hydration. Note that the data obtained in experiments A01PC, A02PC, $\mathrm{A} 03 \mathrm{PC}, \mathrm{A} 04 \mathrm{PC}$ and A05PC all plot on the same trend, regardless of initial sample thickness or porosity. This is because, rather than sample behaviour, the stress-strain relationship reflects the finite stiffness of the deformation apparatus and Instron loading frame. Due to elastic distortion with increasing axial stress, it was impossible to confine the samples perfectly (i.e. impose fixed-position boundary conditions on the sample directly). This implies that the stiffness of the machine determined how much the sample had to expand before the axial stress could increase further, resulting in the stress-displacement shown in Fig. 2c. Figure $2 \mathrm{~d}$ shows axial swelling strain measured after $5 \mathrm{~h}$ of hydration versus the reciprocal of the initial sample thickness. The data produced a linear trend, described by $\Delta L_{5 \mathrm{~h}}=0.174+0.031 L_{0}$.

Since machine distortion was a factor in our measurements (Fig. 2c), we performed a number of position-
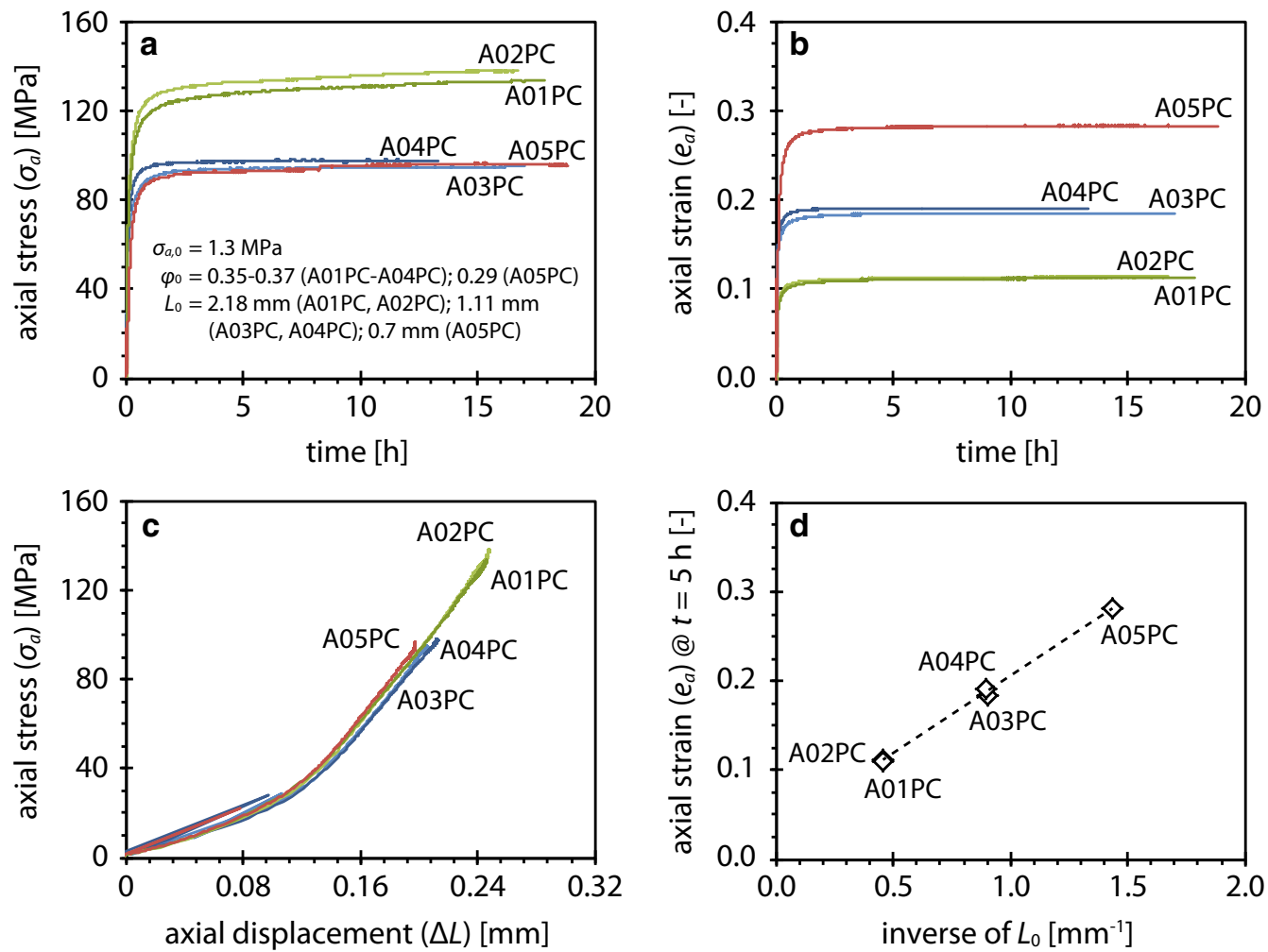

Fig. 2 Mechanical data obtained from $\mathrm{CaO}$ hydration experiments performed in position-control mode, with an initial effective axial stress $\left(\sigma_{0}\right)$ of $\sim 1.3 \mathrm{MPa}$ (A01PC, A02PC, A03PC, A04PC and A05PC-Table 2). a Axial stress versus time, $\mathbf{b}$ axial strain developed in the samples versus time, $\mathbf{c}$ axial stress versus axial displacement (expansion) of the sample and $\mathbf{d}$ axial strain in the samples after $5 \mathrm{~h}$ versus one over the initial sample length 
control experiments at higher initial axial stress (A06PC, $\mathrm{A} 07 \mathrm{PC}$ and A08PC, with $\sigma_{\mathrm{a}, 0}$ of 60,120 and $90 \mathrm{MPa}$, respectively-Table 2). This was done in order to increase the (load-dependent) stiffness of the deformation apparatus, allowing us to assess the effect of improved confinement of the hydrating $\mathrm{CaO}$ samples. The results are shown in Fig. 3, which depicts effective axial stress and axial strain versus time data for these three experiments, together with the data from A01PC and A05PC for reference purposes. Note that the initial sample thickness and porosity were $\sim 0.7 \mathrm{~mm}$ and $\sim 30 \%$ in A05PC, A06PC and A07PC, whereas $L_{0}$ and $\phi_{0}$ measured $2.1-2.3 \mathrm{~mm}$ and $35-40 \%$ in A01PC and A08PC. In general, the axial stresses generated were larger with increasing $\sigma_{\mathrm{a}, 0}$, reaching $146 \mathrm{MPa}$ after $5 \mathrm{~h}$ of hydration in A07PC (Fig. 3a). However, note that the initial response of the samples reacted at $\sigma_{\mathrm{a}, 0}$ values of 60-120 MPa was to compact, as evidenced by small decreases in axial stress at $t<1 \mathrm{~min}$ (Fig. 3b). Figure $3 \mathrm{c}$ shows $\sigma_{\mathrm{a}}$ versus $\Delta L$ data (cf. Fig. 2c), illustrating the machine behaviour. Note that machine stiffness (i.e. the slope of the curves) is constant for a given axial stress. Further note that samples A01PC and A08PC, with comparable $L_{0}$ and $\phi_{0}$, produced comparable axial stresses, while higher $\sigma_{\mathrm{a}, 0}$ resulted in larger stresses to build up in tests A06PC and A07PC. In both sets of experiments, however, axial strain decreased with increasing initial axial stress (Fig. 3d).

\subsubsection{Load-limit experiments}

At the start of measurement, load-limit experiments A09TH and A10TH showed comparable behaviour to position-control experiments A01PC and A02PC. In $\mathrm{A} 09 \mathrm{TH}$ and $\mathrm{A} 10 \mathrm{TH}$, however, Instron operation was transferred to load-control mode once axial stresses of 30 and $60 \mathrm{MPa}$ were attained. From that point onward, the axial load was maintained constant at these values, allowing the samples to expand further at constant stress. Runs A01PC, A02PC, A09TH and A010TH all employed an initial axial load of $\sim 1.3 \mathrm{MPa}$ as well as samples with comparable $L_{0}$ and $\phi_{0}$, ranging 2.09-2.18 mm and 33-36\% (Table 2). Figure 4 shows axial stress and strain versus time data for these experiments, where Fig. 4a, b shows the complete measurements, and Fig. 4c, d shows axial stress and strain evolution during the first hour of hydration. In both experiments A09TH and A10TH, transfer to loadcontrol occurred early on in the measurements ( $t<10 \mathrm{~min}$ ). Maintaining the axial stress at $30 \mathrm{MPa}$ in A09TH resulted in rapid expansion, with a sample strain of nearly $27.5 \%$ developing within $1 \mathrm{~h}$ and reaching a
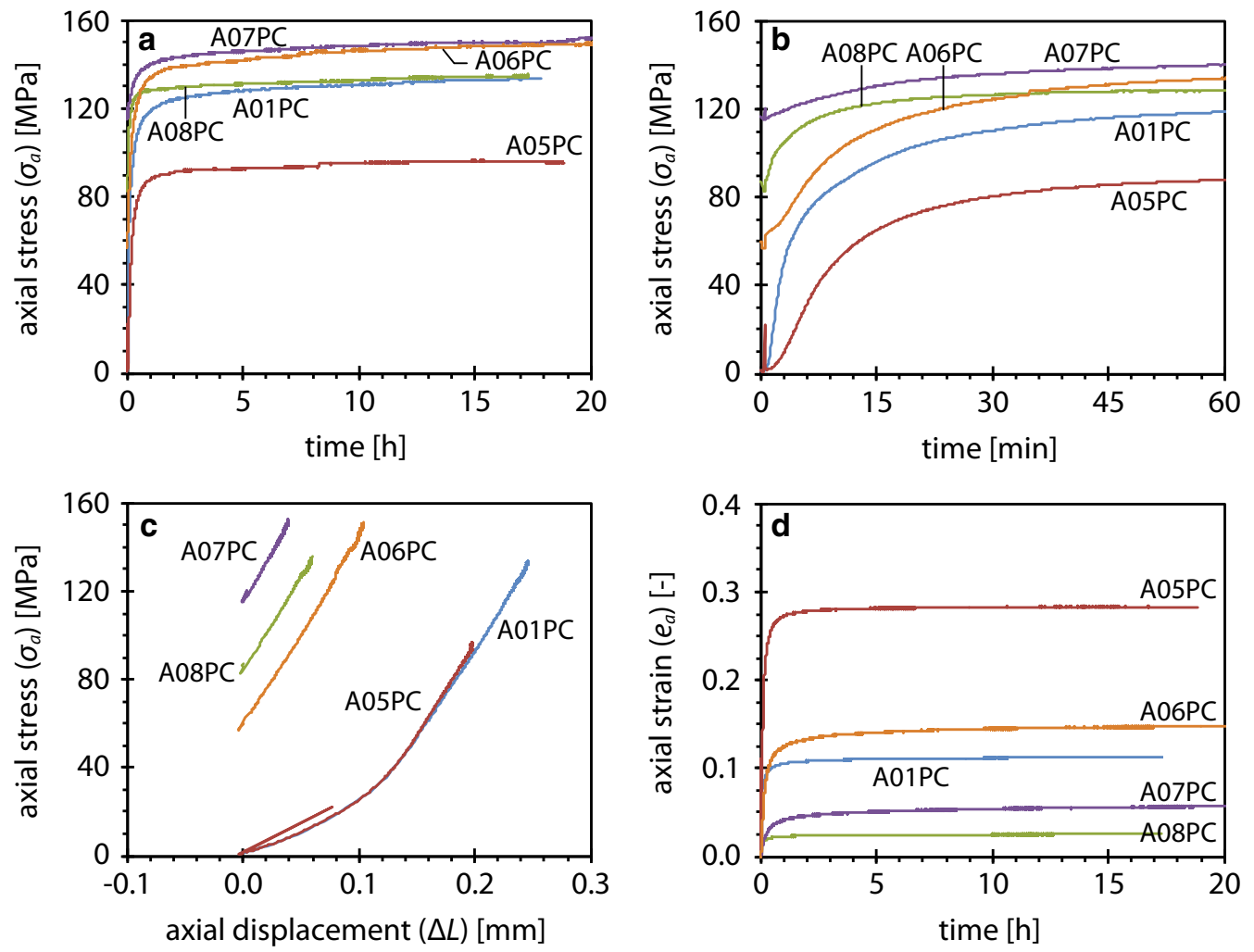

Fig. 3 Mechanical data obtained from $\mathrm{CaO}$ hydration experiments performed in position-control mode, with an initial effective axial stress $\left(\sigma_{0}\right)$ of 60,90 or $120 \mathrm{MPa}$ (A07PC, A08PC and A09TH, respectively-Table 2). a, b Axial stress versus time. c Axial stress versus axial displacement (expansion) of the sample and $\mathbf{d}$ axial strain of the sample versus time 

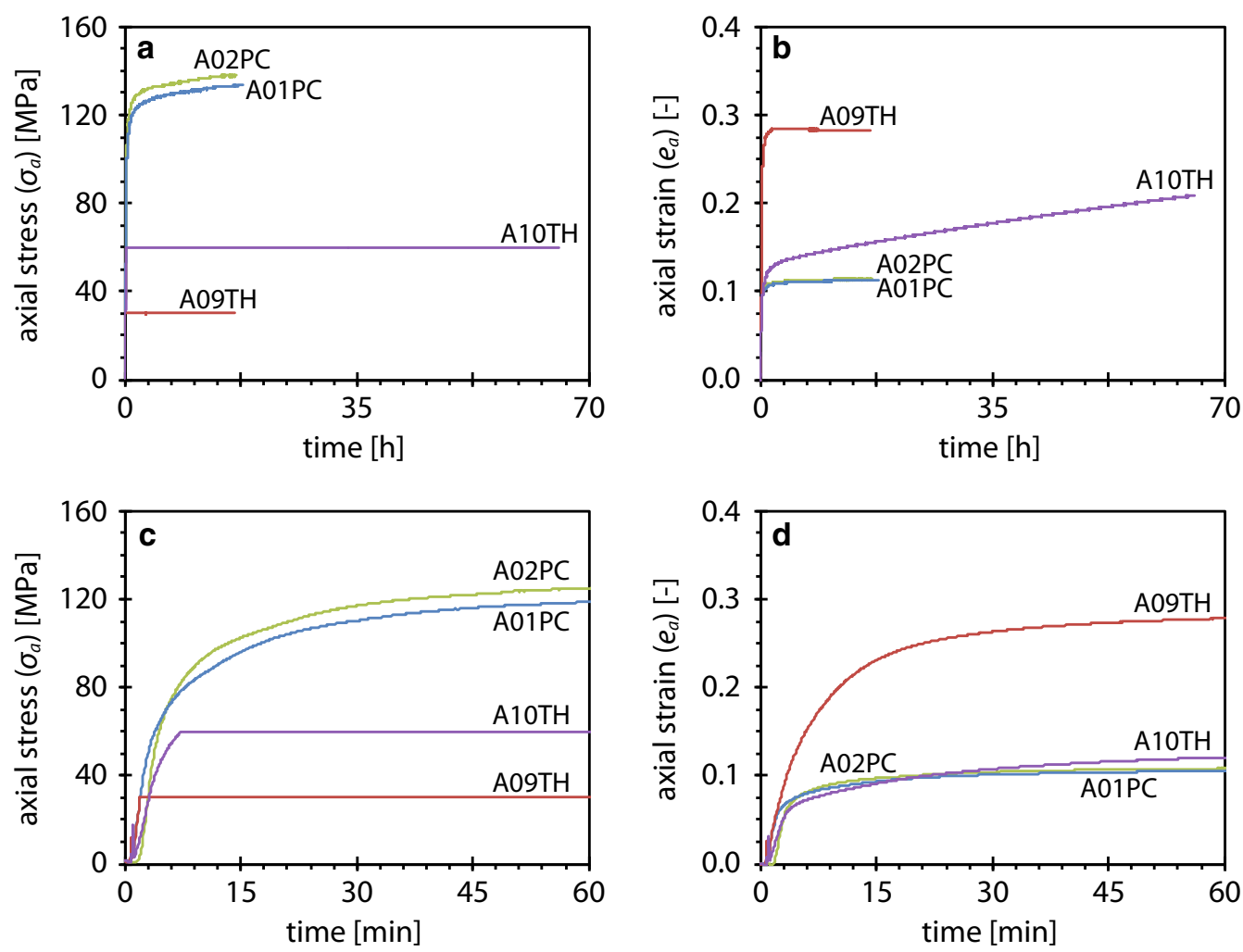

Fig. 4 Mechanical data obtained from load-limit experiments; a, $\mathbf{c}$ axial stress versus time; $\mathbf{b}$, $\mathbf{d}$ axial strain of the samples versus time

maximum value of $28.5 \%$ after $173 \mathrm{~min}$. Note that the sample subsequently compacted, with axial strain slowly decreasing to $28.3 \%$ at test termination after $\sim 17 \mathrm{~h}$ of measurement. Compared to A09TH, maintaining the axial stress at $60 \mathrm{MPa}$ in $\mathrm{A} 10 \mathrm{TH}$ resulted in reduced axial strain, attaining $\sim 11 \%$ after $1 \mathrm{~h}$. However, slow expansion of the sample against the constant stress limit continued for the duration of the test, reaching $20.9 \%$ upon termination at $t \approx 65 \mathrm{~h}$.

\subsubsection{Constant-load experiments}

Figure 5a shows the axial strain versus time data obtained for experiments A11CL, A12CL, A13CL and A14CL, in which the $\mathrm{CaO}$ samples were exposed to water with the Instron in load-control mode from the onset (Table 2). Experiments A11CL, A12CL and A13CL were performed on $\mathrm{CaO}$ samples with $L_{0}$ of about $0.7 \mathrm{~mm}$, and employed operating loads corresponding to axial stresses of 60,120 and $225 \mathrm{MPa}$, respectively. Conversely, sample A14CL had an initial thickness of $\sim 2.1 \mathrm{~mm}$ and was tested under an axial stress of $225 \mathrm{MPa}$. The samples exposed to water under a constant axial stress of 60 or $120 \mathrm{MPa}$ (A11CL and A12CL), i.e. stresses lower than the force of crystallisation that was generated in the constant-position experiments (Sect. 4.1.1), showed sample expansion with time
(Fig. 5a). Conversely, the $\mathrm{CaO}$ samples hydrated under $225 \mathrm{MPa}$ axial stress (A13CL and A14CL) showed compaction, whereby compactive displacement appeared to be independent of $L_{0}$, showing the same amount of displacement for the 0.7 and 2.1 mm-thick samples (Fig. 5b).

\subsection{Microstructural and chemical data}

\subsubsection{Characterisation of the starting $\mathrm{CaO}$ material}

Representative samples of the calcined powder used in the FoC experiments were analysed using a laser diffraction particle sizer technique, SEM and TGA, to characterise the $\mathrm{CaO}$ starting material. The apparent grain size was determined using a Malvern Instruments Mastersizer S long bed instrument, using hexane as the dispersing fluid to minimise hydration during analysis. In four consecutive measurements on the same powder sample, the mean grain size decreased from 144 to $93 \mu \mathrm{m}$ while the grain size distribution narrowed (Fig. 6). The third and fourth Malvern measurements gave comparable results, with a grain size distribution of roughly $95 \pm 60 \mu \mathrm{m}$. SEM observations showed that these "grains" consisted of sintered clusters of about 1-5 $\mu \mathrm{m}$ large particles (Fig. 7a, b). Accordingly, the grain size evolution as seen in the Malvern particle sizer data (Fig. 6) likely reflected disintegration of these 

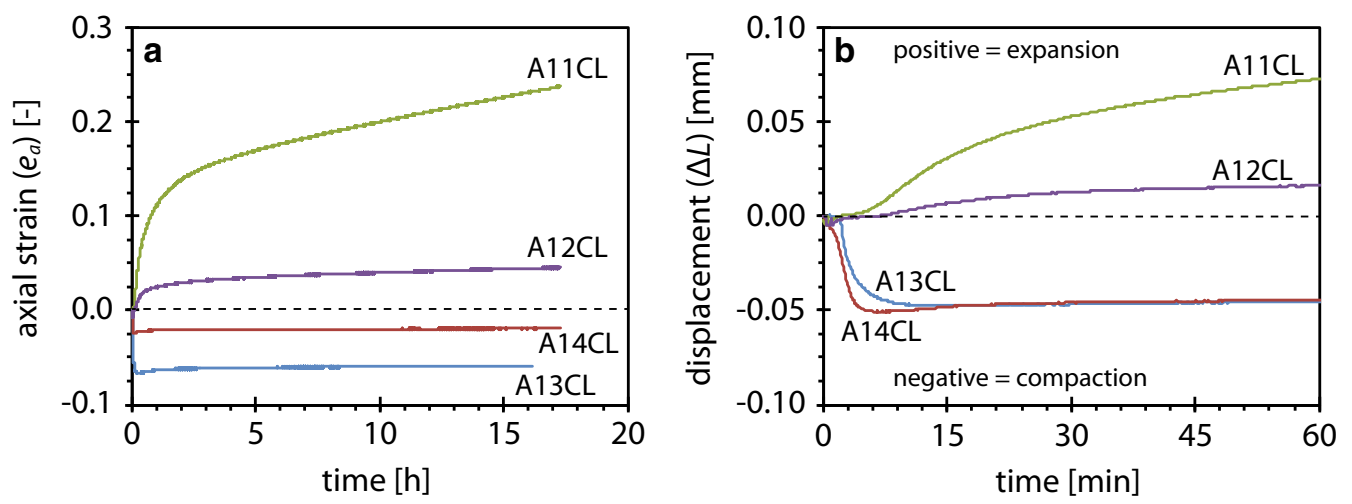

Fig. 5 Mechanical data obtained from $\mathrm{CaO}$ hydration experiments performed in load-control mode, imposing a constant axial stress of 60 (A11CL), 120 (A12CL) or $225 \mathrm{MPa}$ (A13CL and A14CL-Table 2). a Axial strain in the samples versus time; b axial displacement (expansion) of the samples versus time

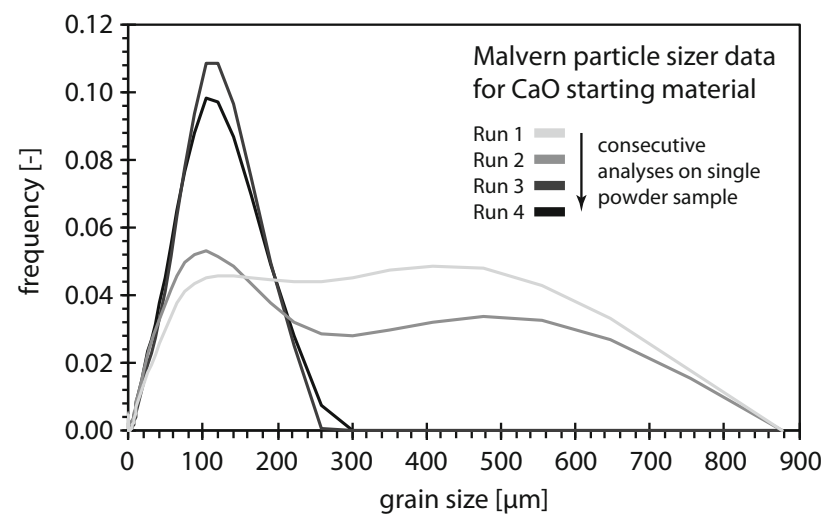

Fig. 6 Apparent grain size of the $\mathrm{CaO}$ starting material as determined using a Malvern Instruments Mastersizer S long bed particle sizer instrument. Four consecutive measurements on the same powder sample are shown. The third and fourth measurements gave comparable results, with a mean grain size of roughly $95 \pm 60 \mu \mathrm{m}$

agglomerates of sintered particles, falling apart as the dispersing fluid was agitated. As such, the character of the $\mathrm{CaO}$ samples is better defined by the 1-5 $\mu \mathrm{m}$ large particles (Fig. 7c), than by the clusters these particles comprise.

Possible hydration and carbonation of the $\mathrm{CaO}$ powder samples during experiment preparation and initial precompaction, i.e. before water injection and starting the force of crystallisation measurement, were investigated using TGA. Contamination by hydration or carbonation prior to testing was minor, with the analysis of a powder that experienced the same preparation procedure as the samples that were hydrated in the deformation apparatus yielding $\mathrm{Ca}(\mathrm{OH})_{2}$ and $\mathrm{CaCO}_{3}$ contents of $<1 \mathrm{wt} \%$, calculated in terms of $\mathrm{CaO}$ equivalents [117].

\subsubsection{Post-experiment observations on the hydrated samples}

Upon removal from the sample assembly, the top side of all samples appeared white or light greyish, glassy and translucent. In some samples, the bottom side was dull and opaque by comparison. However, this zonation was generally not stable, with the white-greyish colouration sometimes visibly migrating downwards through the samples after their retrieval. This presumably reflected ongoing hydration, making it difficult to assess confidently which characteristics of the samples were representative of their condition during the FoC measurements, i.e. under load, and which features were post-experimental artefacts, produced (a) via subsequent hydration during the unloading and cooling of the deformation apparatus, or (b) during sample retrieval and preparation for microstructural analysis.
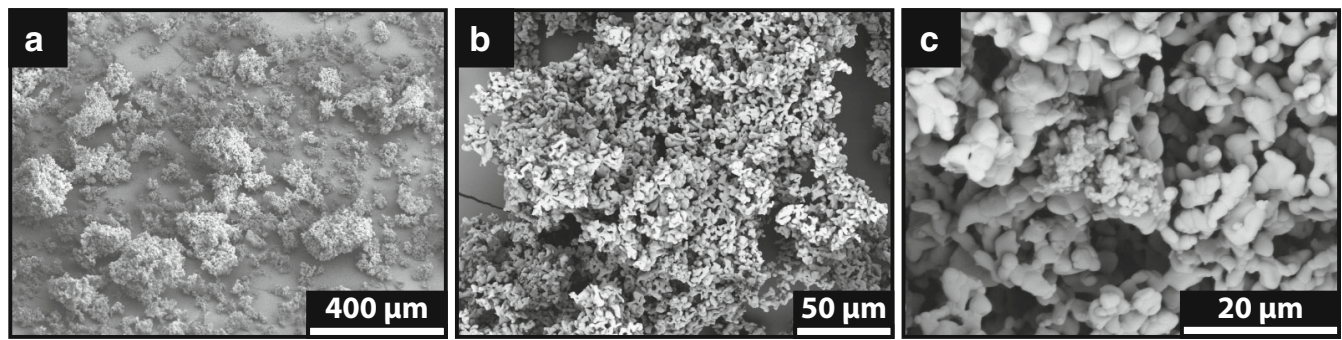

Fig. 7 Secondary electron micrographs of a representative sample of $\mathrm{CaO}$ starting material, imaged at different magnifications 
Samples A03PC, A04PC, A05PC and A09TH formed cohesive pellets (e.g. Fig. 8a), which could easily be retrieved intact. When broken using a razor blade, these samples often displayed a sub-optical, crystalline texture (Fig. 8b), in some cases featuring (remnants of) axially oriented, reaction front-like structures (Fig. 8c). Note that all four these samples experienced axial stresses of $<100 \mathrm{MPa}$ (cf. $\sigma_{\max }$ in Table 2). Samples A01PC, A02PC, A06PC, A07PC, A011CL, A012CL, A013CL and A014CL were more friable. While some of these samples could be obtained relatively intact, most disintegrated into discfractured fragments and powder, either upon sample retrieval or (more often) sometime after (Fig. 8d). It is notable that the white, opaque material at the bottom side of the samples was generally less consolidated and disintegrated into a powder, whereas the white-greyish, translucent material on the top side formed thin (typically 100-500 $\mu \mathrm{m}$ thick) discs that were more cohesive and remained largely intact (Fig. 8e). Sample A10TH was lost and could not be studied microstructurally.

Samples A01PC and A09TH were studied using SEM. Focussing on sample A01PC, the most prominent feature was a $150-200-\mu \mathrm{m}$-wide zone of dense material, present along the top side of the sample, which was most directly exposed to water during testing. This low-porosity zone was broken up into regular segments (Fig. 9a) and
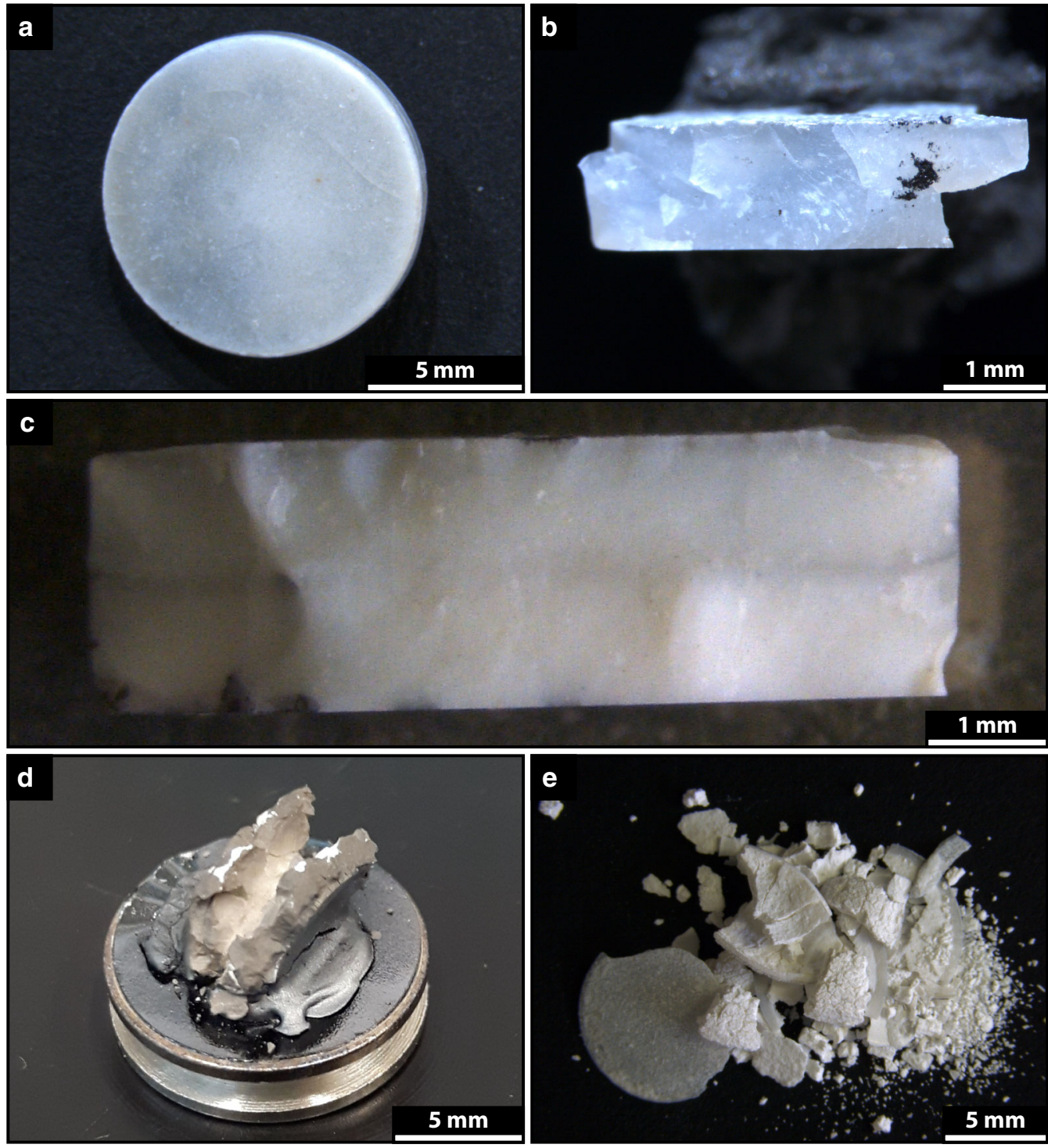

Fig. 8 Optical microscopy images of the hydrated samples. a Sample A04PC, as an example of samples that could be retrieved as wholly cohesive pellets. b Broken surface of sample A03PC, showing cryptocrystalline texture. c Broken surface of sample A09TH, showing cryptocrystalline, dense structure with faint horizontal zonation. d Photograph of sample A01PC on SEM stub, exemplifying post-experiment spalling and disintegration of the samples. e Photograph of sample A07PC, as an example of samples that fell apart upon retrieval, showing a more cohesive top part and a completely disintegrated bottom half 

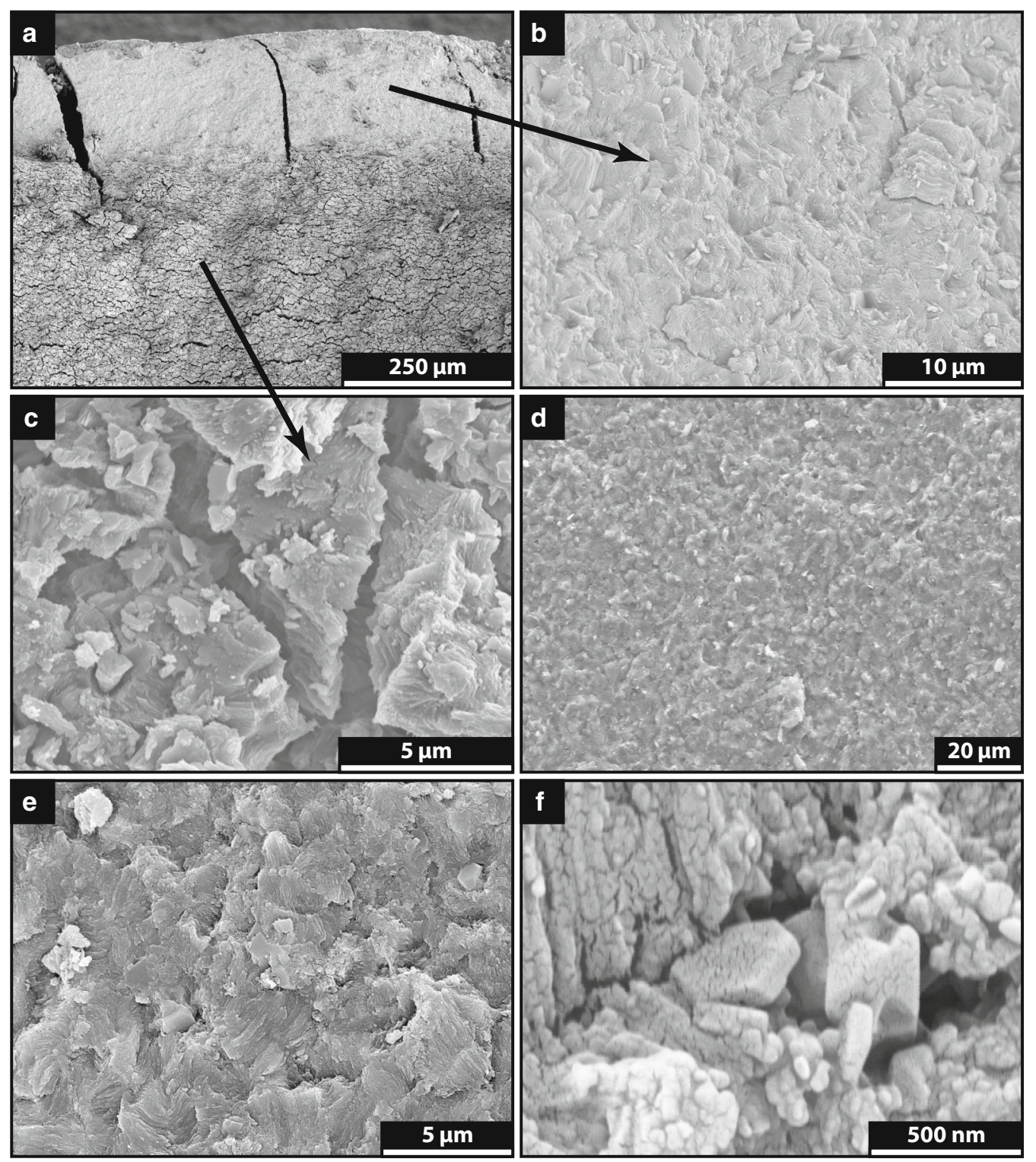

Fig. 9 Secondary electron micrographs of samples A01PC (a-c) and A09TH (d-f). a Part of sample A01PC, showing a 150-200- $\mu$ m-wide, dense, periodically jointed layer at the top of the image, and a heavily fractured, more porous zone below it. Note that the water entered the sample from the top. b Zoomed into the very dense top layer in sample A01PC, showing a feather-like morphology. $\mathbf{c}$ Zoomed into the fractured, more porous bottom part of A01PC, showing otherwise similar morphology to the top part. d Typical view of the microstructure of A09TH, representative for all zones seen in Fig. 8c. e Zoomed image of sample A09TH, showing a dense, feather-like morphology similar to that seen in sample A01PC. f Submicron-sized hexagonal crystals that, based on morphology, are likely portlandite

consisted of a fine grained, fibrous material (Fig. 9b). The remainder of A01PC was heavily fractured/jointed (Fig. 9c). Considering that the sample spalled apart, after it was cut, mounted on a stub and Pt-coated, and before it was studied using SEM (Fig. 8d), these joints may have represented post-experimental hydration, which could also have caused the regular breakup of the top part. Alternatively, the joints in the bottom part and breakup of the top part could be unloading features. Besides being heavily fractured, the bulk of A01PC broadly resembled the lowporosity zone at the top side, consisting of a similar, fibrous material (Fig. 9c). Turning to sample A09TH, the reaction front-like structure present, clearly visible by visual inspection, and detectable under the optical microscope (Fig. 8c), could not be distinguished using SEM. The microstructure consisted mostly of fibrous material, not unlike that seen in sample A01PC (Fig. 9d). In addition to the fibrous material (Fig. 9e), rare, submicron-sized, hexagonal platelets could locally be distinguished (Fig. 9f), which, on the basis of their euhedral crystal-shape, most likely were portlandite [117]. In A09TH, microstructure remained more or less constant in the axial direction. 


\section{Discussion}

The present experiments have successfully recorded the development of axial stress driven by a force of crystallisation during confined hydration of porous $\mathrm{CaO}$ powder samples, at $65^{\circ} \mathrm{C}$ and at atmospheric fluid pressure. Confinement was achieved using an Instron testing machine to limit axial expansion of the sample within the rigid cylindrical die containing the sample. With the Instron ram held in fixed position (position control), sample expansion was accordingly limited to concomitant elastic machine distortion, thus allowing the observed force of crystallisation to develop. We measured hydration-induced axial stresses of up to nearly $153 \mathrm{MPa}$ (Figs. 2, 3, 4, 5; Table 2), which is well in excess of the tensile strength of most rock materials [59] and of in situ lithostatic stress at depths up to $6 \mathrm{~km}$. However, the measured stresses constitute only $\sim 5 \%$ of the maximum value predicted by the thermodynamic theory for FoC (Sect. 2.2.2). Alongside this, the position-controlled experiments showed a decrease in swelling strain with increasing sample thickness (Fig. 2b). Increased initial confining stress, accomplished by increasing the initial axial stress, increased the FoC stresses that developed, but decreased the swelling strains attained (Fig. 3). In experiments where samples were hydrated under constant axial stress, samples subjected to 60 or $120 \mathrm{MPa}$ showed expansion, while those subjected to $225 \mathrm{MPa}$ compacted (Fig. 5). Microstructural observations showed that the samples that supported axial stresses $>100 \mathrm{MPa}$ often contained a dense, cohesive layer, consisting of white or greyish, slightly translucent material and about $100-500 \mu \mathrm{m}$ thick, at the top of the samples, i.e. adjacent to the fluid inlet (Figs. 8e, 9a). By contrast, the remainder of these samples was generally friable and disintegrated over time (Figs. 8d, e, 9a, c).

In the following, we will analyse our experimental data and attempt to explain the observed behaviour and why the GPa stresses predicted by thermodynamic theory were not achieved in the experiments. We go on to discuss the implications with respect to the applicability of FoC processes in achieving wellbore casing expansion and sealing, and consider ways in which the $\mathrm{FoC}$ achievable by $\mathrm{CaO}$ hydration can be increased.

\subsection{Factors affecting FoC development: sample expansion versus machine stiffness}

So far, we have considered the effective stress pertaining at thermodynamic equilibrium (Eqs. 10, 13) to be the maximum FoC-induced stress that can develop due to precipitation of a confined solid product phase. However, strictly speaking, this equilibrium was calculated as the force that the surroundings must exert on a growing crystal to prevent precipitation from occurring. Whether a growing crystal can actually exert this maximum stress on its environment will depend on the degree of confinement and attainable expansion. In our experiments, confinement is imposed by the Instron loading frame and the stress generated by a given sample expansion is controlled by the apparatus stiffness. This is clearly demonstrated in Fig. 2c, where the data plotted show an identical axial stress-axial displacement behaviour to that obtained in independent machine stiffness calibrations. Accordingly, in the present constant-position experiments, the hydration-induced stresses that develop cannot exceed the stress generated by machine distortion equal to the maximum swelling strain of the sample. This means that the FoC we measured is determined by the combined effects of sample swelling plus apparatus stiffness, with finite sample swelling being essential for producing a FoC. Measured sample swelling $\left(\Delta V_{\mathrm{m}}, \Delta L_{\mathrm{m}}\right)$ is in turn determined by the increase in solid volume $\left(\Delta V_{\mathrm{s}}\right)$ caused by converting $\mathrm{CaO}$ to $\mathrm{Ca}(\mathrm{OH})_{2}$, i.e. by the extent of reaction $(\xi)$, plus the change in pore volume of the sample $\left(\Delta V_{\mathrm{p}}\right)$, plus elastic changes in solid grain density (and hence sample volume, $\Delta V_{\mathrm{el}}$ ) due to increasing mean stress in the sample during $\mathrm{FoC}$ development. Changes in pore volume in such a reacting system will in general include a component of pore volume increase $\Delta V_{\mathrm{p}}^{+}(>0)$, due to entrapment and expansion of pores as a direct consequence of reaction, plus a component of pore volume decrease $\Delta V_{\mathrm{p}}^{-}(<0)$ related to stress-driven mechanical compaction involving grain rearrangement/deformation and hence solid redistribution.

On this basis, we can accordingly write $\Delta V_{\mathrm{m}}=\Delta V_{\mathrm{s}}(\xi)+\Delta V_{\mathrm{p}}(\xi, \sigma)+\Delta V_{\mathrm{el}}\left(\xi, \sigma, V_{\mathrm{p}}\right) \quad$ where $\Delta V_{\mathrm{p}}=\Delta V_{\mathrm{p}}^{+}+\Delta V_{\mathrm{p}}^{-}$, which on dividing by the initial sample volume (and assuming no radial strain) gives measured sample strain at any instant as

$e_{\mathrm{m}}=\frac{\Delta V_{\mathrm{m}}}{V_{0}}=\frac{\Delta L_{\mathrm{m}}}{L_{0}}=e_{\mathrm{s}}(\xi)+e_{\mathrm{p}}(\xi, \sigma)+e_{\mathrm{el}}(\xi, \sigma, \phi)$

where each term can be viewed as volumetric strain contributions due to solid conversion $\left(e_{\mathrm{s}}\right)$, permanent pore volume change $\left(e_{\mathrm{p}}\right)$, and elastic deformation of the sample $\left(e_{\mathrm{el}}\right)$. However, as reasoned above, in fixed-position experiments, sample swelling strain and associated axial displacement $\left(\Delta L_{\mathrm{m}}\right)$ are accommodated by apparatus distortion, so that $\Delta L_{\mathrm{m}}=\sigma / C$ where $C$ is the apparatus stiffness (itself a function of stress in our set-up) measured in $\mathrm{Pa} \mathrm{m}^{-1}$. Equivalently, $e_{\mathrm{m}}=\sigma /\left(C L_{0}\right)$. Now, at a given value of reaction extent $(\xi)$ and sample porosity $(\phi)$, $e_{\mathrm{el}}=\sigma / E_{\mathrm{C}}$ where $E_{\mathrm{C}}$ is the instantaneous constrained 
elastic stiffness of the sample. This means we can rewrite Eq. 15 as

$e_{\mathrm{m}}-e_{\mathrm{el}}=\frac{\sigma}{C L_{0}}-\frac{\sigma}{E_{\mathrm{C}}}=e_{s}(\xi)+e_{p}(\xi, \sigma)$

In general, however, $E_{\mathrm{C}} \gg C L_{0}$ (elastic stiffness of the sample is much greater than of the much larger machine), so that $e_{\mathrm{el}} \ll e_{\mathrm{m}}$ and $e_{\mathrm{el}}$ can be neglected, yielding $e_{\mathrm{m}} \approx e_{\mathrm{s}}(\xi)+e_{\mathrm{p}}(\xi, \sigma)$ or $\Delta V_{\mathrm{m}} \approx \Delta V_{\mathrm{s}}(\xi)+\Delta V_{\mathrm{p}}(\xi, \sigma)$. In addition, the FoC-driven stress that develops during reaction of a given sample tested in fixed-position mode can be written as $\sigma \approx C L_{0}\left(e_{\mathrm{s}}(\xi)+e_{\mathrm{p}}(\xi, \sigma)\right)$. This is important to analysing and interpreting our experimental results.

\subsection{Analysis of sample volume changes and implications for mechanism controlling FoC}

Having established that the build-up of a FoC requires sample volume expansion, let us now consider in detail the different volumetric strain contributions that have occurred in our experiments. Given the molar volumes of $\mathrm{CaO}$, $\mathrm{Ca}(\mathrm{OH})_{2}$ and water (Table 1), complete reaction of $\mathrm{CaO}$, with a given (excess) volume of water, to form $\mathrm{Ca}(\mathrm{OH})_{2}$, involves an increase in the solid volume of $\sim 1.6 \times 10^{-5}$ $\mathrm{m}^{3} \mathrm{~mol}^{-1}$, i.e. almost a doubling if reaction proceeds as given in Eq. 12. By contrast, the total solid-plus-fluid volume decreases by $\sim 2 \times 10^{-6} \mathrm{~m}^{3} \mathrm{~mol}^{-1}$. In our experiments, the hydration reaction contributes to the strain $e_{\mathrm{s}}$ (solid volume change $\Delta V_{\mathrm{s}}$ ) according to the extent of reaction $(\xi)$.

\subsubsection{Endmember strain development scenarios}

To progress further, it is useful to analyse the sample volume changes $\left(\Delta V_{\mathrm{m}}, e_{\mathrm{m}}\right)$ that can occur in a set of endmember scenarios that are relevant for our experiments. Figure 10 shows that maximum attainable volumetric strain as a function of initial porosity for four such scenarios. The first two scenarios (Fig. 10, dashed curves denoted S1a and S1b) represent closed-system endmember behaviour. Here, the initial sample porosity is water-filled (e.g. established by vacuum-flushing at the start of experiment), but no further water can enter the samples, i.e. the system is closed with respect to pore fluid transport. For realistic initial porosities of $\phi_{0}<52 \%$, the maximum extent of reaction is then determined by the availability of water, and conversion of quicklime to portlandite will be incomplete. Scenarios S1a and S1b differ in how sample porosity evolves. In S1a (Fig. 10), the initial pore volume is maintained, i.e. solid product phases do not occupy the initial pore space. This should be considered an upper limit for expansion, unlikely to be attained in practice. Scenario $\mathrm{S} 1 \mathrm{~b}$ represents the cases where porosity goes to zero during hydration, thus representing the minimum swelling associated with complete initial pore water consumption. The other two scenarios addressed in Fig. 10 (dotted curves denoted S2a and S2b) consider open systems, where water can freely enter or leave the samples (e.g. through the bore of the top piston in our experiments), thus allowing $\mathrm{CaO}$ hydration to go to completion regardless of initial porosity. Scenarios S2a and S2b again differ in how the sample

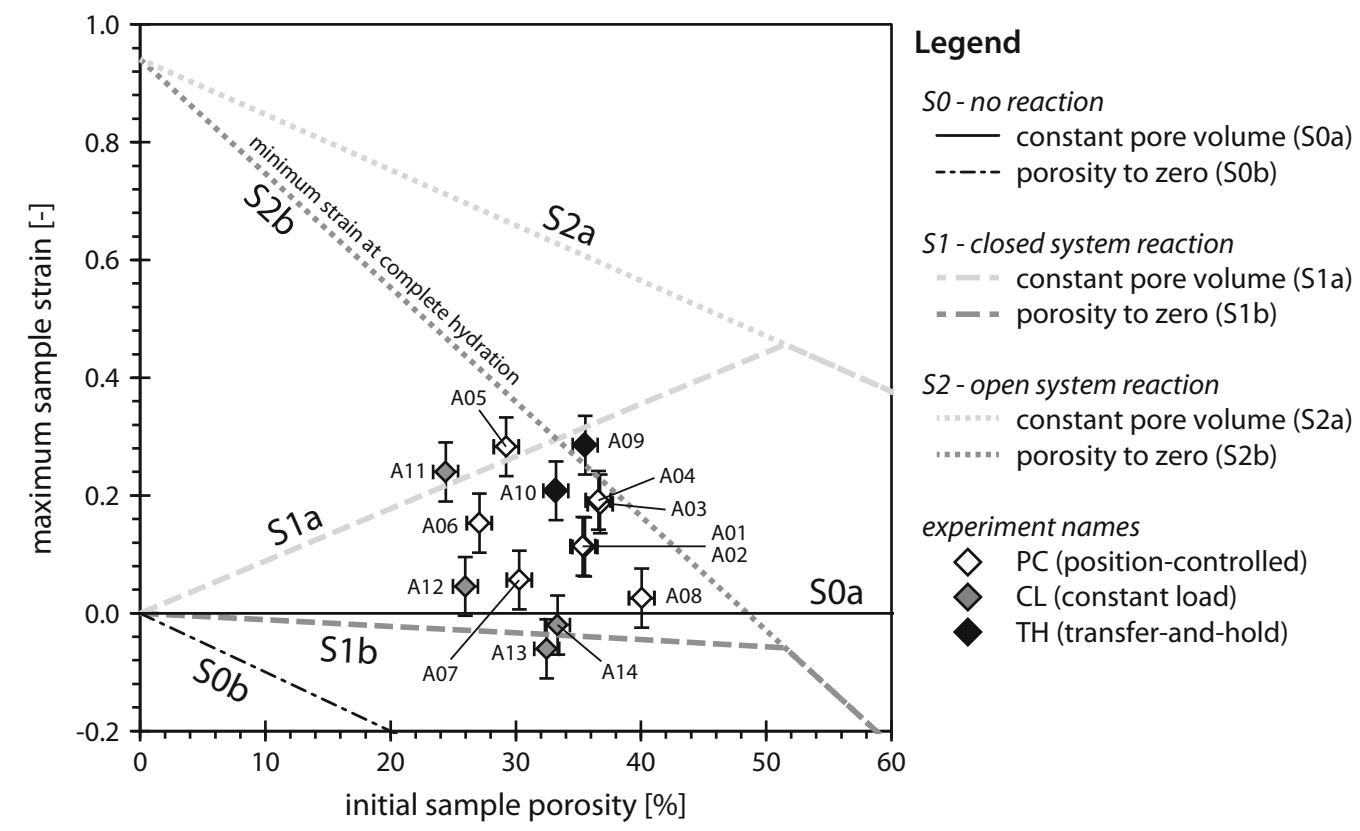

Fig. 10 Maximum attainable sample strain versus starting porosity for different reaction scenarios, together with final sample strain versus initial porosity data for our $\mathrm{CaO}$ samples 
porosity evolves with reaction, with S2a being characterised by a constant pore volume, similar to S1a. In scenario $S 2 b$, similar to $S 1 b$, sample porosity is assumed to go to zero, so that the plotted strains represent minimum values for complete (open system) $\mathrm{CaO}$ hydration. While the evolution of porosity $(\phi)$ is undetermined in our experiments, assuming that the porosity of highly hydrated material approaches zero is likely reasonable, given the dense, translucent nature of the hydrated portions of our hydrated samples (Figs. 8b, c, 9b, d). Initial sample porosity $\left(\phi_{0}\right)$ is known from $\phi_{0}=1-m_{0} /\left(\rho_{\mathrm{CaO}} L_{0} A\right)$.

Also plotted in Fig. 10 are our experimental data, specifically the final axial strains attained in our experiments versus the initial sample porosity. Error bars represent uncertainty in our data related to initial sample length and sample porosity determinations.

\subsubsection{Role of reaction extent in determining stress development}

The first thing to note in Fig. 10 is that all samples but A03PC, A04CP and A09TH plot below the dark grey, dotted curve corresponding to the scenario S2b of complete hydration (open-system reaction) plus complete porosity reduction. This implies that, within uncertainty of the strain measurements, stress development in position-controlled experiments A03PC and A04PC could possibly have been limited by hydration going to completion, i.e. the system reaching chemical equilibrium by eliminating all $\mathrm{CaO}$, before higher axial stresses developed. Experiment A09TH was conducted in load-limit mode, with $\sigma_{T H}=30 \mathrm{MPa}$, allowing reaction to proceed without the build-up of stress beyond this value, potentially attaining complete hydration. However, in all other samples tested (A01PC, A02PC, A05PC, A06PC, A07PC, A08PC, A10TH, A11CL, $\mathrm{A} 12 \mathrm{CL}, \mathrm{A} 13 \mathrm{CL}$ and $\mathrm{A} 14 \mathrm{CL}$ ), the measured sample strains are less than the minimum value expected for complete hydration (S2b). In general, it is likely that sample porosity did not go to zero, but instead attained some small residual value, which would have contributed to the final volumetric expansion. These measured strains must therefore imply that $\mathrm{CaO}$ hydration was incomplete at the time of experiment termination in the majority of the samples. Accordingly, the limited stresses in most experiments, particularly in position-controlled experiments A01PC, A02PC, A05PC, A06PC, A07PC and A08PC, cannot be explained by the system running out of $\mathrm{CaO}$ to hydrate. This further implies that larger swelling strains should have been possible in experiments A01PC, A02PC, A05PC, A06PC, $\mathrm{A} 07 \mathrm{PC}$ and $\mathrm{A} 08 \mathrm{PC}$, were reaction to proceed. It follows that the axial stresses developed here were not limited by insufficient machine stiffness but by incomplete reaction progress and net expansion.

\subsubsection{The role of transport processes and water access}

Given the zoned nature (Figs. 8c, 9a) and brittle/friable post-experiment character of our samples, with many of them spalling (Fig. 8d) or partially crumbling into a powder (Fig. 8e), our microstructural data strongly support the notion that the hydration reaction was incomplete in many of the experiments. Indeed, with $\mathrm{CaO}$ remaining in the samples after completion of the experiments (i.e. following unloading), any ongoing hydration via the air could subsequently have caused internal expansions, explaining the observed disintegration of the samples (cf. [113]). On the other hand, some of the samples, which either were very thin (A03PC, A04PC, A05PC), or experienced low load (A09TH), did form dense cohesive pellets (Sect. 4.2.2), suggesting that a larger extent of reaction occurred in these experiments. Indeed, spalling may be a consequence of differential expansion during unloading. We therefore need to consider what processes and effects may have contributed to this variability in extent of reaction occurring during our experiments. A clear candidate is the question of water access into the reacting sample from the external fluid system, i.e. the issue of the evolving permeability of the (reacted part of the) sample during the reaction progress.

Lacking post-experiment sample mass measurements, there is no direct means of determining the extent of reaction in our experiments, as the volume of water consumed and hence total system volume with time, are unknown. However, as discussed above, some constraints can be obtained by comparing measured sample strain, which represents the combined effect of hydration-induced changes in solid volume (i.e. extent of reaction) and porosity change, with the endmember scenarios represented in Fig. 10. Returning to Fig. 10, all samples except A13CL and A14CL plot well above the line corresponding to scenario $\mathrm{S} 1 \mathrm{~b}$, representing complete porosity reduction plus closed-system reaction. This means that the measured strain is more than can be explained by closed-system behaviour, assuming strong porosity reduction, suggesting that at least some water entered our samples during the hydration process in addition to that initially injected. Transport of water into the sample porosity certainly occurred in samples A05PC and A11CL, as the data for these experiments plot above the constraint corresponding to closed-system reaction at constant pore volume (scenario S1a). Further, we note that experiments A13CL and A14CL, which plot below the scenario S1b line, were conducted in load-control mode, at a constant and high axial stress of $225 \mathrm{MPa}$. These samples showed compaction rather than expansion (Fig. 5). For A13CL and A14CL, we therefore infer that hydration (i.e. solid volume increase), combined with compaction of the reacting 
sample material under the large applied axial stress, rapidly reduced porosity and permeability when water was first introduced, thus quickly limiting the potential for inflow of additional water and strongly limiting reaction. Based on volumetric strain considerations, the extent of hydration (with respect to open-system conditions) was $<60 \%$ in A13CL and A14CL.

Evidence for complete hydration was encountered only in A09TH (Fig. 10). The sample retrieved from this experiment formed a dense pellet, and its strain/initial porosity data plot slightly above the scenario S2b line in Fig. 10, i.e. the constraint that corresponds to open-system reaction plus complete porosity reduction. It is important to note that A09TH was a load-limit experiment, in which we used a low axial stress limit of $30 \mathrm{MPa}$. As such, hydration occurred under much lower axial stresses than was the case in any of the other samples (Table 2). We infer that water remained able to enter the sample under these conditions, allowing ongoing expansion in the approach to complete hydration (Figs. 2a, b, 4a, b). The observed subsequent compaction of A09TH (Fig. 4b) further suggests that grain boundaries were still wetted at this point (allowing compaction mechanisms such as pressure solution to operate), and that at least some porosity remained (to compact into). Load-limit experiment A10TH, employing an axial stress limit of $60 \mathrm{MPa}$, also shows continued sample expansion during nearly $70 \mathrm{~h}$ of testing, though at a slower rate (Fig. 4). Similar behaviour is seen in load-controlled experiments A11CL and A12CL, employing constant axial stresses of 60 and $120 \mathrm{MPa}$, respectively (Fig. 5). Indeed, by comparing the data for samples A09TH, A10TH, A11CL and A12CL, we observe that in all cases expansion and/or stress development continues throughout the experiments, but the rate slows down markedly with increasing axial stress, indicating that the apparent rate of $\mathrm{CaO}$ hydration slows down with increasing axial stress.

On basis of the above, and since hydration was found to be incomplete in most of our samples at the time of experiment termination, we infer that the development of a FoC, and hence the stresses we measured, depends on the availability and inward transport of water from outside the original pore volume. In turn, we have clear indications, as discussed above, that access of water to the samples strongly depended on axial stress (Figs. 4, 5). Combined, the above observations bring us back to the key assumptions in the thermodynamic theory for FoC development, namely that an aqueous phase must be present to allow reaction and must remain present in stressed contacts $[22,23,105]$, for instance in the form of a thin film or occupying a microchannel network. Alternatively stated, the presence of a fluid phase is imperative for continued reaction and precipitation of the solid product phase, while grain boundary wetting and pore connectivity are essential for the development of a force of crystallisation. Based on our data and limited microstructural observations, the implication is that the combined effects of reaction progress, $\mathrm{Ca}(\mathrm{OH})_{2}$ precipitation and build-up of axial stress led to the shutdown of the pore network and hence transport pathways for water into samples, and/or to the disconnection of, or expulsion of water films from, grain interfaces.

To facilitate comparison between position-controlled and load-controlled experiments, we plotted sample displacement after $5 \mathrm{~h}$ versus initial axial stress, as shown in Fig. 11. In this graph, sample displacement can be regarded as a measure of a sample's capacity to generate a force of crystallisation. Note that sample displacement also is directly related to swelling strain, hence the extent of reaction in our samples. The initial axial stress can be considered a measure for the resistance against expansion. We observe a monotonic decrease in sample displacement with increasing initial axial stress, transgressing from net expansion to net compaction. Since expansion is a requirement for a FoC-driven axial stress to develop, this implies that the stress required to cut off water access to the samples in our experiments was of the order of 150-175 MPa. It should be noted, however, that these values represent the overall stress on the sample, and the stresses at grain contacts may be higher, e.g. if force chains occur.

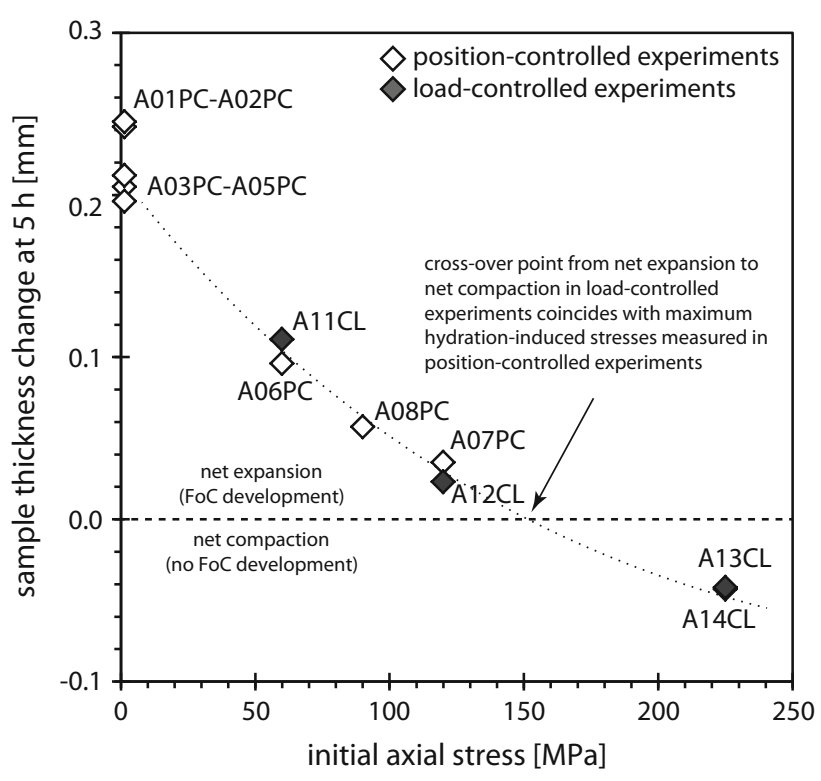

Fig. 11 Axial displacement (expansion or compaction) of the samples measured after $5 \mathrm{~h}$ of hydration versus the initial axial stress applied in the experiments. Both our position-controlled and loadcontrolled experiments delineate a decreasing trend in axial displacement with increasing stress, transgressing from net expansion to net compaction around 150-175 MPa 


\subsubsection{Transport path shutdown mechanisms}

Several different processes could play a role in the shutdown of transport pathways and grain contact fluid films (Fig. 12). As the already fine $(\sim 5 \mu \mathrm{m}) \mathrm{CaO}$ particles hydrate, an even finer $\mathrm{Ca}(\mathrm{OH})_{2}$ nanocrystalline mush will be produced (cf. [73]). This presumably is weak and deforms by frictional granular flow or even diffusion or pressure solution accommodated granular flow [96, 131]. Accordingly, the $\mathrm{Ca}(\mathrm{OH})_{2}$ phase could easily become extruded from hydrating $\mathrm{CaO}$ grain contacts into the intervening pores, leading to mechanical compaction of the $\mathrm{CaO}$ framework and to a reduction in sample porosity and permeability. The pore-sizes in the $\mathrm{Ca}(\mathrm{OH})_{2}$ mush will presumably be very small (less than the grain size), so that the permeability of regions filled with this reaction product a fine $\mathrm{Ca}(\mathrm{OH})_{2}$ product obstructs $\mathrm{CaO}$ porosity b $\mathrm{Ca}(\mathrm{OH})_{2}$ product compacts as FoC stress increases

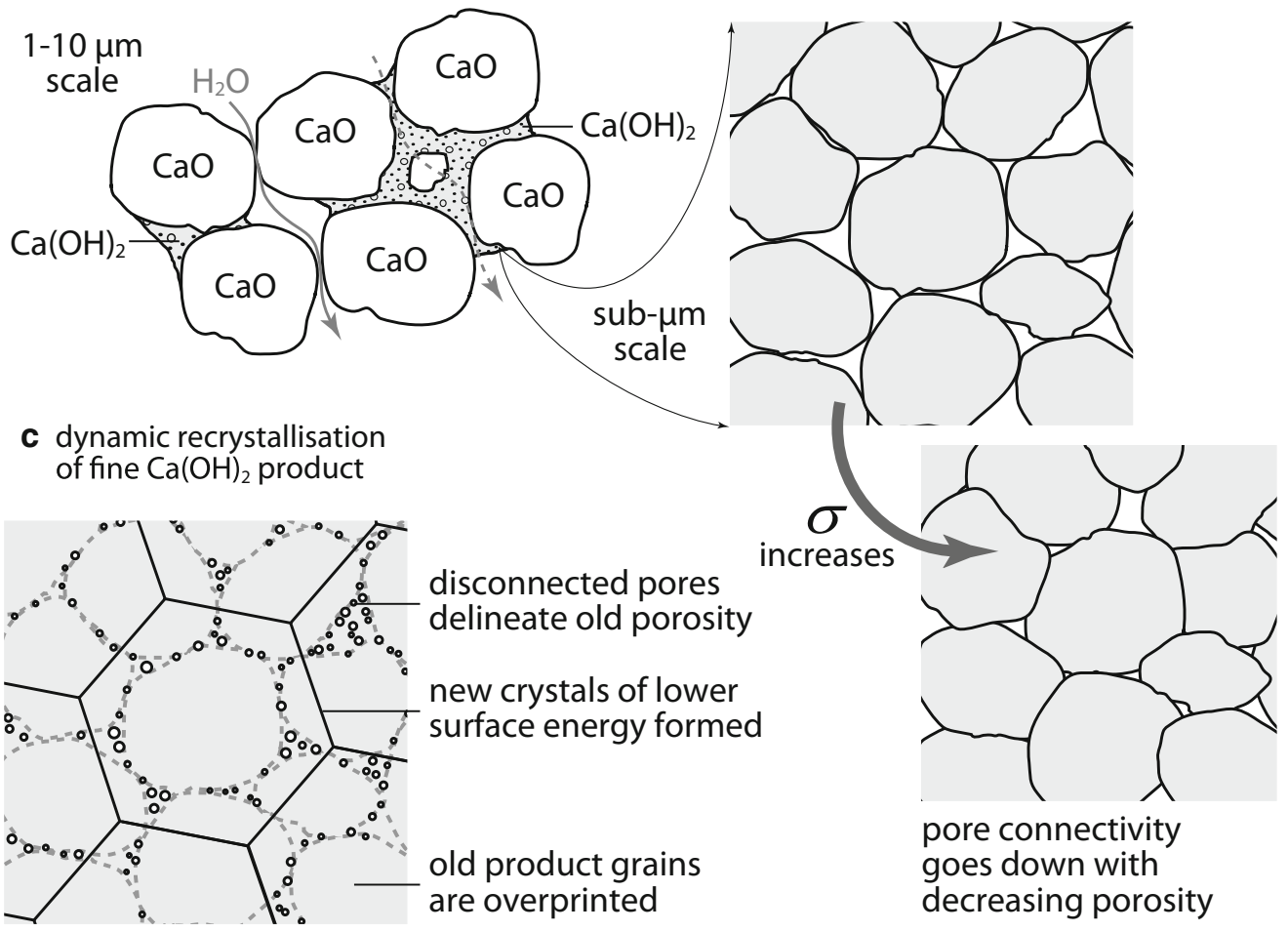

d sintering, neck growth and grain contact healing of fine $\mathrm{Ca}(\mathrm{OH})_{2}$
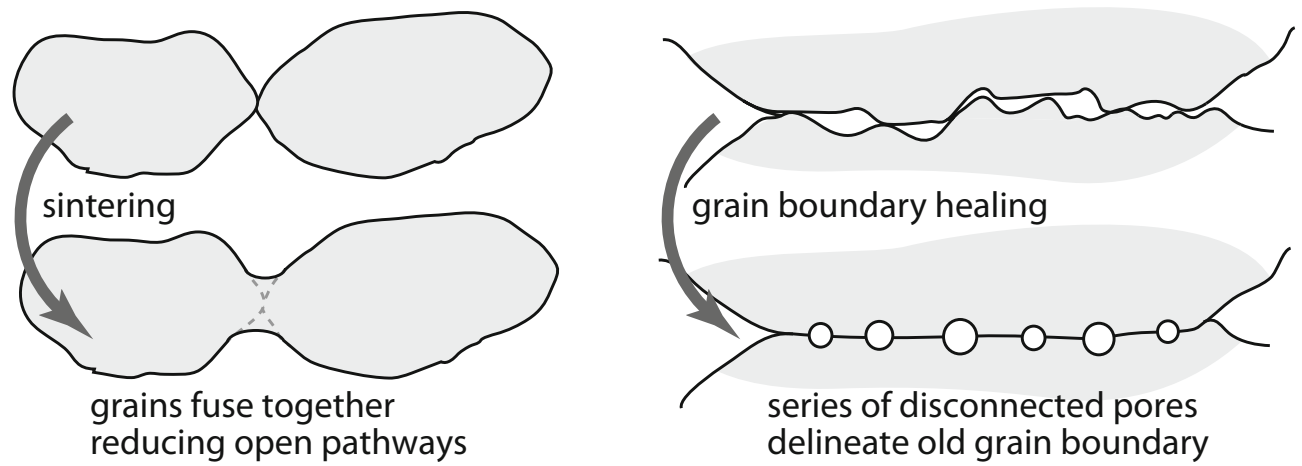

Fig. 12 Schematic representation of the compaction and densification mechanisms that may play a role in the shutdown of transport pathways for water into the hydrating $\mathrm{CaO}$ samples. a The fine $\mathrm{Ca}(\mathrm{OH})_{2}$ formed during hydration may extrude into the pore space, reducing connectivity. b As stress builds up due to reaction, both the $\mathrm{CaO}$ framework and newly formed $\mathrm{Ca}(\mathrm{OH})_{2}$ mush may compact. c Dynamic recrystallisation and grain growth may lead grain boundaries to disconnect into strings of isolated pores. d Mechanisms such as sintering, neck growth and grain contact healing may aid permeability reduction 
will be low, even if the porosity remains connected. More likely, though, the material will cement up by reactiondriven precipitation or by grain growth and sintering processes, promoting permeability reduction. Moreover, at free, unloaded surfaces such as larger pore walls between hydrating $\mathrm{CaO}$ grains or $\mathrm{Ca}(\mathrm{OH})_{2}$ grain clusters, the solution phase will be supersaturated with respect to $\mathrm{Ca}(\mathrm{OH})_{2}$, leading to precipitation in pore throats, rapidly reducing permeability and restricting water access, preventing further reaction.

As load generated by expansion is progressively transferred to the product mush, due to elimination of the initially load-supporting $\mathrm{CaO}$ framework, the nanocrystalline $\mathrm{Ca}(\mathrm{OH})_{2}$ product phase may further compact via pressure solution plus intergranular sliding. This will further reduce the porosity and permeability of the $\mathrm{Ca}(\mathrm{OH})_{2}$ produce and whole sample until healing of the grain contacts occurs by internal or contact margin precipitation, i.e. via contact asperity or neck growth phenomena [122, 123]. As indicated above, grain growth involving grain boundary migration, driven by surface energy reduction in the fine product phase, could also disconnect pores and reduce permeability simply by overgrowing and isolating pores [69]. This grain growth could potentially occur during filling of larger pores with fine $\mathrm{Ca}(\mathrm{OH})_{2}$ reaction product, blocking the pores very quickly and trapping fluid. Another explanation would be that fluid infiltration and hence reaction progress is facilitated by reaction-induced fracturing [92], with build-up of higher normal stresses hampering the opening of such microfractures.

Alternatively to the above clogging mechanisms limiting reaction progress and hence FoC development, the stresses measured in our experiments may correspond to attaining or exceeding the effective normal stress required to displace a fluid film from a flat grain-to-grain contact, i.e. the so-called disjoining pressure [57, 105, 106]. Exceeding this pressure could lead to "drying-out" of the stressed grain contacts, impeding further reaction/hydration and dissolution/precipitation at these locations. When precipitation takes place on pore walls, this will lead to porosity reduction, which may cut off permeability. However, this will also result in more grain-grain contacts, i.e. a larger load-bearing surface area, thus bringing the maximum possible stress on a sample scale closer to the maximum possible stress from thermodynamic calculations. Unfortunately, to our knowledge, there have been no studies published in which the disjoining pressure between calcium hydroxide and calcium oxide surfaces, and various combinations thereof, was measured or calculated. We therefore have no basis upon which to evaluate this hypothesis further. Moreover, the exact surface area of the loaded contacts within our $\mathrm{CaO}$ samples is unknown, precluding direct comparison even if such data would be available. Nevertheless, it is interesting to note that our experimental data show a transition from net expansion to net compaction at an axial stress of $150-175 \mathrm{MPa}$ (Fig. 11). This transition could perhaps represent complete cessation of FoC development, e.g. due to healing of grain boundaries, but could also reflect a regime shift in the (relative) kinetics of compaction and expansion, e.g. due to water transport limitations or local depletion of $\mathrm{CaO}$. Such a competition between hydration-induced expansion and stress-induced compaction may explain the late-stage compaction observed in A09TH (Fig. 4b).

Last, it should be noted that, given the relatively short duration of our laboratory experiments, we cannot rule out the possibility that $\mathrm{CaO}$ hydration did not stop in our experiments but merely slowed down, due to increasingly constricted inflow of water, to the point where the build-up of further stress became negligible on the timescale of our experiments (up to $\sim 65 \mathrm{~h}$ ). In Portland-based cement, residual (i.e. unhydrated) clinker phases can remain present for years [117], demonstrating that restricted water availability can slow down reaction, even in the absence of high stress.

\subsection{Applicability to casing expansion and suggestions for future work}

In Introduction, we raised the question of whether the force of crystallisation generated during confined hydration of $\mathrm{CaO}$ [43] can be used to expand the casing of leaking wellbores, thus achieving sealing, e.g. via the construction of some form of internal plug using a CaO-based material. We argued that if sufficiently high internal stresses can be attained, then hydration of the plug may bring about a permanent radial expansion of the casing pipe, thereby closing the annular voids and fractures that constitute leakage pathways outside of the casing [74, 75]. However, any such application of $\mathrm{CaO}$ hydration-induced stresses would require the stresses and strains that develop during $\mathrm{CaO}$ hydration to be predictable and controllable.

Our experiments on precompacted $\mathrm{CaO}$ powder samples have shown the development of $\mathrm{CaO}$ hydration-induced stresses of up to $153 \mathrm{MPa}$ (Fig. 11). Preliminary calculations, made using Barlow's formula for plastic yielding of a cylindrical metal pipe [7, 124], show that stresses in the range of 100-300 $\mathrm{MPa}$ are required to initiate expansion of a typical wellbore casing constructed from conventional steel [56]. Therefore, while noting that the true stress requirements will be wellbore specific and require analysis of the geomechanical state of the wellbore, our preliminary laboratory results are quite encouraging. On the other hand, the hydration-induced stresses measured in our experiments constitute only a small fraction of the GPa stresses predicted by thermodynamic theory, so there remains scope 
for further study and attempts to increase achievable reaction-driven stress. The main goal of such work should be to elucidate the mechanism underlying the shutdown of water transport, which seems to have arrested FoC development in our experiments. A possible first step in this direction would be to conduct $\mathrm{CaO}$ hydration experiments similar to ours, but using a controlled fluid pressure, and a deformation apparatus with flow-through capability, to monitor sample permeability. This type of set-up would further allow for the investigation of certain additives, such as mineral phases with grossly different surface energies, porous ceramics particles, or glass fibre, which could potentially help maintain the transport pathways for water open for longer.

In addition, the following two aspects of FoC development by $\mathrm{CaO}$ hydration require further study, from both a scientific and an application perspective. First, our experiments involved $\mathrm{CaO}$ powder samples that were precompacted at $250 \mathrm{MPa}$ to reduce initial porosity. Conducting a similar procedure on an industrial scale would be costly. It would therefore be interesting to study in more detail the effect of initial porosity on the development and maximum magnitude of the force of crystallisation, e.g. to determine allowable porosity ranges for the method to be workable. Second, in the present study we prepared our $\mathrm{CaO}$ by calcining Carrara marble at $1100{ }^{\circ} \mathrm{C}$ for $16 \mathrm{~h}$. There exists a substantial body of literature dealing with the effects of calcination temperature, starting carbonate material and grain size, and various other processes (e.g. sintering) on the nature of the final $\mathrm{CaO}$ product $[13,14,41,46,112]$. For example, the rate of hydration is slower for dead-burnt lime (calcined at $>1600^{\circ} \mathrm{C}$ ) than for "normal" $\mathrm{CaO}$, prepared at $<1200{ }^{\circ} \mathrm{C}$ [43]. Larger FoC-induced stresses could potentially be generated by optimising properties of the $\mathrm{CaO}$ material used.

\section{Conclusions}

This study was motivated by noting that leakage of $\mathrm{CO}_{2}$ or other fluids occurring behind the steel casing in a wellbore could potentially be mitigated by producing a small radial expansion of the casing by means of hydration of $\mathrm{CaO}$, thus mechanically closing annular voids, debonding defects and/or fractures outside the casing. For the hydration of $\mathrm{CaO}$, thermodynamic models predict reaction are capable of producing very large stresses, or forces of crystallisation (FoC), in the range of $3.4 \mathrm{GPa}$. However, the stresses produced by $\mathrm{CaO}$ hydration have never been directly measured in the laboratory. To assess what FoC-induced stresses can be attained in practice, we studied their development in uniaxial expansion experiments on precompacted (at $250 \mathrm{MPa}$ axial stress) powder aggregates of
$\mathrm{CaO}$ (precompacted discs with initial porosities of $24.9-40 \%$ and initial thicknesses of $0.68-2.34 \mathrm{~mm}$ ), which were one-sidedly exposed to water a temperature of $65^{\circ} \mathrm{C}$. Our main findings can be summarised as follows:

1. In experiments where $\mathrm{CaO}$ powder aggregates were hydrated under confined conditions, i.e. where axial (volumetric) expansion of the samples was limited to that allowed due to the finite stiffness of the deformation apparatus, we observed that samples continued to expand until effective axial stresses of up to $153 \mathrm{MPa}$ were generated. While these stresses are substantial, they constitute only about $5 \%$ of the thermodynamically predicted maximum. Volumetric considerations, accounting for both reaction-induced changes in solid volume and the possible range of porosity reduction, suggest that in at least some of these experiments hydration cannot have been complete. Note that hydration was also incomplete in the test where $153 \mathrm{MPa}$ axial stress was achieved.

2. In experiments where the hydration of $\mathrm{CaO}$ powder aggregates proceeded under a constant axial stress, we observed a decrease in the swelling strain with increasing axial stress, from 60 to $120 \mathrm{MPa}$, while samples that were hydrated under $225 \mathrm{MPa}$ showed compaction rather than expansion. Volumetric considerations show that the extent of reaction was $<60 \%$ in the experiments performed at $225 \mathrm{MPa}$. In terms of the observed axial displacement, about $50 \mu \mathrm{m}$ of compaction occurred, regardless of sample thickness, suggesting the responsible process occurred in a limited region. Plotting the measured sample expansion versus initial axial stress showed a transition from net expansion to net compaction around 150-175 MPa.

3. The samples that experienced axial stresses of $<100$ MPa formed dense, cohesive pellets, displaying a cryptocrystalline texture. Conversely, in samples subjected to $>100 \mathrm{MPa}$, microstructural analysis revealed very dense, about $100-300 \mu \mathrm{m}$ thick rims, present at the top of the samples (which was directly exposed to water). The remainder of these samples was comparatively porous, and rather friable, with these parts of the samples often disintegrating into a powder. We infer this represents ongoing, post-experiment hydration of these parts of the samples.

4. Given our stress measurements, there must be a process that stops or significantly slows down the rate of hydration, well before the thermodynamic maximum stress is attained. In only a few of the experiments could this be attributed to hydration reaching completion. This notion of partial hydration is substantiated by our microstructural observations, with 
samples for which volumetric considerations suggest incomplete hydration showing thin, dense zones developed at the top side, where water entered the samples. We infer that the development of such dense zones by the combined effects of sample cementation and stress-driven compaction led to shutdown of transport pathways for water into the sample pore structure and into grain contacts. Moreover, a key assumption in the thermodynamic model, namely that a solution phase, for instance in the form of thin films or microchannels, remains present may not hold at high grain boundary contact stresses, corresponding to our measured sample-scale stresses of about 150-175 MPa, e.g. due to a disjoining pressure effect.

5. With regard to possible application to leakage remediation in wellbores, the present laboratory experiments documented hydration-induced stresses of a magnitude equivalent to that of the internal pressures required for casing expansion. However, the development of these stresses is strongly dependent on the influx of water, which may yield practical limitations. Nevertheless, the present results point the way to finding engineering solutions that may in future allow controllable, reactioninduced stresses and strains to be achieved and applied in wellbore sealing operations. For example, usage of certain additives may help maintain transport pathways for water open longer, which could potentially allow larger stresses to develop.

Acknowledgements Data used in this paper were acquired in experiments performed at the High Pressure and Temperature Laboratory, Utrecht University, the Netherlands. Data can be made available by the authors upon request. We thank Eimert de Graaff, Gert Kastelein, Peter van Krieken and Thony van der Gon Netscher for valuable technical support provided in the laboratory and Bart Verberne for help with using the Scanning Electron Microscope. The manuscript benefitted from the detailed feedback of two anonymous reviewers, for which we are thankful. This research was conducted within the context of CATO-2 (www.co2-cato.org), the Dutch national research program on Carbon Capture and Storage (CCS). The program is financially supported by the Dutch government (Ministry of Economic Affairs) and the CATO-2 consortium parties.

Open Access This article is distributed under the terms of the Creative Commons Attribution 4.0 International License (http:// creativecommons.org/licenses/by/4.0/), which permits unrestricted use, distribution, and reproduction in any medium, provided you give appropriate credit to the original author(s) and the source, provide a link to the Creative Commons license, and indicate if changes were made.

\section{References}

1. Agbasimalo N, Radonjic M (2014) Experimental study of the impact of drilling fluid contamination on the integrity of cement-formation interface. J Energy Resour Technol 136:42908

2. Anderson GM, Crerar DA (1993) Thermodynamics in geochemistry: the equilibrium model. Oxford University Press, Oxford

3. Bachu S (2003) Screening and ranking of sedimentary basins for sequestration of $\mathrm{CO}_{2}$ in geological media in response to climate change. Environ Geol 44:277-289. doi:10.1007/s00254-0030762-9

4. Bachu S, Watson T (2006) Possible indicators for $\mathrm{CO}_{2}$ leakage along wells. In: 8th International conference on greenhouse gas control technologies, pp 19-22

5. Barclay I, Pellenbarg J, Tettero F, Pfeiffer J (2001) The beginning of the end: a review of abandonment and decommissioning practices. Oilf Rev 13(4):28-41

6. Bargawi RA, Zhou S, Al-Umran MI, Aghnim WA (2005) Expandable tubular successfully scab off severe casing leaks. In: SPE/IADC middle east drilling technology conference and exhibition, 12-14 September, Dubai, United Arab Emirates. Society of Petroleum Engineers. doi:10.2118/97357-MS

7. Barlow $\mathrm{P}$ (1836) On the force excited by hydraulic pressure in a Bramah press; the resisting power of the cylinder, and rules for computing the thickness of metal for presses of various powers and dimensions. Trans Inst Civ Eng 1:133-139. doi:10.1680/ itrcs. 1836.24488

8. Bauer S, Beyer C, Dethlefsen F, Dietrich P, Duttmann R, Ebert M, Feeser V, Görke U, Köber R, Kolditz O, Rabbel W, Schanz T, Schäfer D, Würdemann H, Dahmke A (2013) Impacts of the use of the geological subsurface for energy storage: an investigation concept. Environ Earth Sci 70:3935-3943. doi:10.1007/ s12665-013-2883-0

9. Becker GF, Day AL (1905) The linear force of growing crystals. Proc Wash Acad Sci 8:238-288

10. Becker GF, Day AL (1916) Note on the linear force of growing crystals. J Geol 24:313-333

11. Beruto D, Barco L, Belleri G, Searcy AW (1981) Vapor phase hydration of submicrometer $\mathrm{CaO}$ particles. J Am Ceram Soc 64:74-80

12. Birss FW, Thorvaldson $T$ (1955) The mechanism of the hydration of calcium oxide. Can J Chem 33:881-886

13. Borgwardt RH (1989) Sintering of nascent calcium oxide. Chem Eng Sci 44:53-60

14. Bruce KR, Gullett BK, Beach LO (1989) Comparative $\mathrm{SO}_{2}$ reactivity of $\mathrm{CaO}$ derived from $\mathrm{CaCO}_{3}$ and $\mathrm{Ca}(\mathrm{OH})_{2}$. AIChE J 35:37-41

15. Brufatto C, Cochran J, Conn L, Power D, El-Zeghaty SZAA, Fraboulet B, Griffin T, James S, Munk T, Justus F (2003) From mud to cement-building gas wells. Oilfield Rev. 15:62-76

16. Bruhns W, Mecklenburg W (1913) Über die sogennante Kristallisationskraft. Jahresbericht des Niedersächsischen Geol. Vereins zu Hann. VI

17. Brunet J-PL, Li L, Karpyn ZT, Huerta NJ (2016) Fracture opening or self-sealing: critical residence time as a unifying parameter for cement- $\mathrm{CO}_{2}$-brine interactions. Int J Greenh Gas Control 47:25-37

18. Byrom TG (2014) Casing and liners for drilling and completion: design and application. Elsevier, Amsterdam

19. Campbell K, Smith R (2013) Permanent Well Abandonment. Way Ahead 9:25-27

20. Cao P, Karpyn ZT, Li L (2015) Self-healing of cement fractures under dynamic flow of $\mathrm{CO}_{2}$-rich brine. Water Resour Res. doi:10.1002/2014WR016162

21. Chatterji S (1995) Mechanism of expansion of concrete due to the presence of dead-burnt $\mathrm{CaO}$ and $\mathrm{MgO}$. Cem Concr Res 25:51-56 
22. Correns CW (1949) Growth and dissolution of crystals under linear pressure. Discuss Faraday Soc 5:267-271

23. Correns CW, Steinborn W (1939) Experimente zur Messung und Erklärung der sogenannten Kristallisationskraft. Z Krist Mater 101:117-133

24. Coussy O (2005) Poromechanics of freezing materials. J Mech Phys Solids 53:1689-1718. doi:10.1016/j.jmps.2005.04.001

25. Cowan M (2007) Field study results improve squeeze cementing success. In: Production and operations symposium, 31 March-3 April, Oklahoma City, Oklahoma, USA. Society of Petroleum Engineers. doi:10.2118/106765-MS

26. Daccord G, Craster B, Ladva H, Jones T, Manescu G (2006) Cement-formation interactions. In: Nelson EB, Guillot D (eds) Well cementing. Schlumberger, Sugar Land, p 773

27. de Boer RB (1977) On the thermodynamics of pressure solution-interaction between chemical and mechanical forces. Geochim Cosmochim Acta 41:249-256

28. de Meer S, Spiers CJ, Nakashima S (2005) Structure and diffusive properties of fluid-filled grain boundaries: an in situ study using infrared (micro) spectroscopy. Earth Planet Sci Lett 232:403-414

29. de Meer S, Spiers CJ, Peach CJ, Watanabe T (2002) Diffusive properties of fluid-filled grain boundaries measured electrically during active pressure solution. Earth Planet Sci Lett 200:147-157

30. Di Crescenzo D, Shuster M, Petlyuk A, Ernens D, Zijsling D, Pasaribu H (2015) Lubricants and accelerated test methods for expandable tubular application. In: SPE/IADC drilling conference and exhibition, 17-19 March, London, England, UK. Society of Petroleum Engineers. doi:10.2118/173111-MS

31. Duchesne J, Reardon EJ (1995) Measurement and prediction of portlandite solubility in alkali solutions. Cem Concr Res 25:1043-1053

32. Dupal KK, Campo DB, Lofton JE, Weisinger D, Cook RL, Bullock MD, Grant TP, York PL (2001) Solid expandable tubular technology - a year of case histories in the drilling environment. In: SPE/IADC drilling conference, 27 February-1 March, Amsterdam, Netherlands. Society of Petroleum Engineers. doi:10.2118/67770-MS

33. Dusseault MB, Gray MN, Nawrocki PA (2000) Why oilwells leak: cement behavior and long-term consequences. In: SPE international oil and gas conference and exhibition, SPE 64733. p 8. doi:10.2118/64733-MS

34. Dyer S, Graham G (2002) The effect of temperature and pressure on oilfield scale formation. J Pet Sci Eng 35:95-107. doi:10.1016/S0920-4105(02)00217-6

35. Espinosa Marzal RM, Scherer GW (2008) Crystallization of sodium sulfate salts in limestone. Environ Geol 56:605-621. doi:10.1007/s00254-008-1441-7

36. Everett DH (1961) The thermodynamics of frost damage to porous solids. Trans Faraday Soc 57:1541-1551

37. Flatt RJ, Scherer GW (2008) Thermodynamics of crystallization stresses in DEF. Cem Concr Res 38:325-336. doi:10.1016/j. cemconres.2007.10.002

38. Flatt RJ, Steiger M, Scherer GW (2006) A commented translation of the paper by C.W. Correns and W. Steinborn on crystallization pressure. Environ Geol 52:187-203. doi:10.1007/ s00254-006-0509-5

39. Fleckenstein WW, Eustes AW, Miller MG (2000) Burst induced stresses in cemented wellbores. In: SPE/AAPG western regional meeting. Society of Petroleum Engineers

40. Fletcher RC, Merino E (2001) Mineral growth in rocks: kineticrheological models of replacement, vein formation, and syntectonic crystallization. Geochim Cosmochim Acta 65:3733-3748. doi:10.1016/S0016-7037(01)00726-8
41. Fuertes AB, Alvarez D, Rubiera F, Pis JJ, Marban G, Palacos JM (1991) Surface area and pore size changes during sintering of calcium oxide particles. Chem Eng Commun 109:73-88

42. Gasda SE, Bachu S, Celia MA (2004) Spatial characterization of the location of potentially leaky wells penetrating a deep saline aquifer in a mature sedimentary basin. Environ Geol 46:707-720. doi:10.1007/s00254-004-1073-5

43. Ghofrani R, Plack H (1993) CaO- and/or MgO-swelling cements: a key for providing a better annular sealing? In: SPE/ IADC drilling conference. Society of Petroleum Engineers. doi:10.2118/25697-MS

44. Gibbs JW (1928) The collected works of J. Willard Gibbs, volume I: thermodynamics. Yale University Press, New Haven

45. Glasson DR (1958) Reactivity of lime and related oxides. II. Sorption of water vapour on calcium oxide. J Appl Chem 8:798-803

46. Glasson DR (1958) Reactivity of lime and related oxides. I. Production of calcium oxide. J Appl Chem 8:793-797

47. Gratier J-P, Frery E, Deschamps P, Røyne A, Renard F, Dysthe D, Ellouz-Zimmerman N, Hamelin B (2012) How travertine veins grow from top to bottom and lift the rocks above them: the effect of crystallization force. Geology 40:1015-1018

48. Harada T, Idemitsu T, Watanabe A, Takayama S (1989) The design method for the demolition of concrete with expansive demolition agents. In: Shah SP, Swartz SE (eds) Fracture of concrete and rock: SEM-RILEM international conference June 17-19, 1987, Houston, Texas, USA. Springer, New York, pp 47-57. doi:10.1007/978-1-4612-3578-1_5

49. Henry KS (2000) A review of the thermodynamics of frost heave. ERDC/CRREL-TR-00-16. Cold Regions Research and Engineering Laboratory, US Army Corps of Engineers, Washington DC

50. Hepple RP, Benson SM (2005) Geologic storage of carbon dioxide as a climate change mitigation strategy: performance requirements and the implications of surface seepage. Environ Geol 47:576-585. doi:10.1007/s00254-004-1181-2

51. Hofstee C, Seeberger F, Orlic B, Mulders F, Van Bergen F, Bisschop R (2008) The feasibility of effective and safe carbon dioxide storage in the De Lier gas field. First Break 26:53-57

52. Hou MZ, Bauer S, Kolditz O, Xie H, Li X, Yang C, Yuan Y (2013) Use of the geological subsurface for production, storage and conversion of clean energy. In: ISRM SINOROCK 2013, 18-20 June, Shanghai, China. International Society for Rock Mechanics

53. Huerta NJ, Hesse MA, Bryant SL, Strazisar BR, Lopano C (2016) Reactive transport of $\mathrm{CO}_{2}$-saturated water in a cement fracture: application to wellbore leakage during geologic $\mathrm{CO}_{2}$ storage. Int J Greenh Gas Control 44:276-289. doi:10.1016/j. ijggc.2015.02.006

54. Idiart AE, López CM, Carol I (2011) Chemo-mechanical analysis of concrete cracking and degradation due to external sulfate attack: a meso-scale model. Cem Concr Compos 33:411-423. doi:10.1016/j.cemconcomp.2010.12.001

55. Ingraffea AR, Wells MT, Santoro RL, Shonkoff SBC (2014) Assessment and risk analysis of casing and cement impairment in oil and gas wells in Pennsylvania, 2000-2012. Proc Natl Acad Sci 111:10955-10960. doi:10.1073/pnas.1323422111

56. ISO 11960 (2004) Petroleum and natural gas industries-steel pipes for use as casing or tubing for wells. Int. Organ. Stand. Geneva

57. Israelachvili JN (2011) Intermolecular and surface forces: revised third edition. Academic Press, New York

58. Jackson RE, Dusseault MB (2014) Gas release mechanisms from energy wellbores. ARMA 14-7753

59. Jaeger J, Cook NG, Zimmerman RW (2007) Fundamentals of rock mechanics, 4th edn. Wiley, New York 
60. Jamtveit B, Malthe-Sørenssen A, Kostenko O (2008) Reaction enhanced permeability during retrogressive metamorphism. Earth Planet Sci Lett 267:620-627. doi:10.1016/j.epsl.2007.12. 016

61. Jamtveit B, Putnis CV, Malthe-Sørenssen A (2008) Reaction induced fracturing during replacement processes. Contrib Mineral Petrol 157:127-133. doi:10.1007/s00410-008-0324-y

62. Jordan MM, Kemp S, Sorhaug E, Sjursaether K, Freer B (2003) Effective management of scaling from and within carbonate oil reservoirs, North Sea Basin. Chem Eng Res Des 81:359-372. doi:10.1205/02638760360596919

63. Kaiser MJ (2015) Decommissioning forecast in the deepwater Gulf of Mexico, 2013-2033. Mar Struct 41:96-126. doi:10. 1016/j.marstruc.2014.12.006

64. Kalil IA, McSpadden AR (2012) Casing burst stresses in particulate-filled annuli: where is the cement? SPE Drill Complet 27:473-485

65. Kamb WB (1959) Theory of preferred crystal orientation developed by crystallization under stress. J Geol 67(2):153-170

66. Kamb WB (1961) The thermodynamic theory of nonhydrostatically stressed solids. J Geophys Res 66:259-271

67. Kelemen PB, Hirth G (2012) Reaction-driven cracking during retrograde metamorphism: olivine hydration and carbonation. Earth Planet Sci Lett 345:81-89

68. Kelemen PB, Matter J, Streit EE, Rudge JF, Curry WB, Blusztajn J (2011) Rates and mechanisms of mineral carbonation in peridotite: natural processes and recipes for enhanced, in situ $\mathrm{CO}_{2}$ capture and storage. Annu Rev Earth Planet Sci 39:545-576. doi:10.1146/annurev-earth-092010-152509

69. Kennedy LA, White JC (2001) Low-temperature recrystallization in calcite: mechanisms and consequences. Geology 29:1027-1030

70. Keulen NT, Den Brok SWJ, Spiers CJ (2001) Force of crystallisation of gypsum during hydration of synthetic anhydrite rock. In: 13th DRT conference: deformation mechanisms, rheology, and tectonics

71. Khaimov-Mal'kov VYa, (1959) Experimental measurement of crystallization pressure. In: Shubnikov AV, Sheftal' NN (eds) Growth of crystals, vol 2. Springer, US, pp 14-19

72. Khaimov-Mal'kov VY (1959) The thermodynamics of crystallization pressure. In: Shubnikov AV, Sheftal' NN (eds) Growth of crystals, vol 2. Springer, US, pp 3-13

73. Kudłacz K, Rodriguez-Navarro C (2014) The mechanism of vapor phase hydration of calcium oxide: implications for $\mathrm{CO}_{2}$ capture. Environ Sci Technol 48:12411-12418. doi:10.1021/ es5034662

74. Kupresan D, Heathman J, Radonjic M (2013) Application of a new physical model of expandable casing technology in mitigation of wellbore leaks. J Can Energy Technol Innov 1(5):1-4

75. Kupresan D, Heathman J, Radonjic M (2014) Experimental assessment of casing expansion as a solution to microannular gas migration. In: IADC/SPE drilling conference and exhibition, 4-6 March, Fort Worth, Texas, USA. Society of Petroleum Engineers. doi:10.2118/168056-MS

76. Ladva HKJ, Craster B, Jones TGJ, Goldsmith G, Scott D (2005) The cement-to-formation interface in zonal isolation. SPE Drill Complet. doi:10.2118/88016-PA

77. Lecampion B, Bunger A, Kear J, Quesada D (2013) Interface debonding driven by fluid injection in a cased and cemented wellbore: modeling and experiments. Int J Greenh Gas Control 18:208-223. doi:10.1016/j.ijggc.2013.07.012

78. Lehner FK (1990) Thermodynamics of rock deformation by pressure solution. In: Barber DJ, Meredith PG (eds) Deformation processes in minerals, ceramics and rocks. Springer, pp 296-333
79. Lehner FK (1995) A model for intergranular pressure solution in open systems. Tectonophysics 245:153-170

80. Lewis K, Zyvoloski GA, Kelkar S, Carey JW (2012) Coupled stress and flow along interfaces in the wellbore environment in relation to $\mathrm{CO}_{2}$ sequestration. In: 46th US rock mechanics/geomechanics symposium. American Rock Mechanics Association

81. Liversidge D, Taoutaou S, Agarwal S (2006) Permanent plug and abandonment solution for the North Sea. In: SPE Asia Pacific oil and gas conference and exhibition, 11-13 September, Adelaide, Australia. Society of Petroleum Engineers. doi:10. 2118/100771-MS

82. Lothenbach B, Matschei T, Möschner G, Glasser FP (2008) Thermodynamic modelling of the effect of temperature on the hydration and porosity of Portland cement. Cem Concr Res 38:1-18

83. Mainguy M, Longuemare P, Audibert A, Lécolier E (2007) Analyzing the risk of well plug failure after abandonment. Oil Gas Sci Technol Rev 62:311-324. doi:10.2516/ogst

84. Marbun B (2006) Kinetik der Hydratation von $\mathrm{CaO}$ und $\mathrm{MgO}$. Technischen Universität Clausthal, Clausthal-Zellerfeld

85. Matschei T, Lothenbach B, Glasser FP (2007) Thermodynamic properties of Portland cement hydrates in the system $\mathrm{CaO}$ $\mathrm{Al}_{2} \mathrm{O}_{3}-\mathrm{SiO}_{2}-\mathrm{CaSO}_{4}-\mathrm{CaCO}_{3}-\mathrm{H}_{2} \mathrm{O}$. Cem Concr Res 37:1379-1410

86. McLellan AG (1968) The chemical potential in thermodynamic systems under non-hydrostatic stresses. In: Proceedings of the Royal Society of London A: mathematical, physical and engineering sciences. The Royal Society, pp 1-13

87. Means WD, Li T (2001) A laboratory simulation of fibrous veins: some first observations. J Struct Geol 23:857-863

88. Meng Q, Xie Z, Feng L (2003) An introduction to the expandible casing technology. Drill Prod Technol 4:23

89. Merino E, Dewers T (1998) Implications of replacement for reaction-transport modeling. J Hydrol 209:137-146. doi:10. 1016/S0022-1694(98)00150-4

90. Montgomery CT (2006) Implications of cementing for well production and performance. In: Nelson EB, Guillot D (eds) Well cementing. Schlumberger, Sugar Land, p 773

91. Nelson EB, Guillot D (eds) (2006) Well cementing, 2nd edn. Schlumberger, Sugar Land

92. Noiriel C, Renard F, Doan M-L, Gratier J-P (2010) Intense fracturing and fracture sealing induced by mineral growth in porous rocks. Chem Geol 269:197-209

93. Orlic B (2009) Some geomechanical aspects of geological $\mathrm{CO}_{2}$ sequestration. KSCE J Civ Eng 13:225-232. doi:10.1007/ s12205-009-0225-2

94. Ostapenko GT (1976) Excess pressure on the solid phases generated by hydration (according to experimental data on the hydration of periclase). Traslated Geokhimikiya 6:824-844

95. Paterson MS (1973) Nonhydrostatic thermodynamics and its geologic applications. Rev Geophys 11:355-389

96. Paterson MS (1995) A theory for granular flow accommodated by material transfer via an intergranular fluid. Tectonophysics 245:135-151

97. Plumper O, Royne A, Magraso A, Jamtveit B (2012) The interface-scale mechanism of reaction-induced fracturing during serpentinization. Geology 40:1103-1106. doi:10.1130/G33390.1

98. Pluymakers AMH, Peach CJ, Spiers CJ (2014) Diagenetic compaction experiments on simulated anhydrite fault gouge under static conditions. J Geophys Res Solid Earth 119:4123-4148

99. Procesi M, Cantucci B, Buttinelli M, Armezzani G, Quattrocchi F, Boschi E (2013) Strategic use of the underground in an energy mix plan: synergies among $\mathrm{CO}_{2}, \mathrm{CH}_{4}$ geological storage and geothermal energy. Latium Region case study (Central 
Italy). Appl Energy 110:104-131. doi:10.1016/j.apenergy.2013. 03.071

100. Putnis A, Janssen A, Jamtveit B, Putnis CV (2009) Reactioninduced fracturing during replacement reactions. Geochim Cosmochim Acta Suppl 73:1061

101. Ramachandran VS, Sereda PJ, Feldman RF (1964) Mechanism of hydration of calcium oxide. Nature 201:288-289

102. Ravi K, Bosma M, Gastebled O (2002) Safe and economic gas wells through cement design for life of the well. SPE 75700

103. Røyne A, Dysthe DK (2012) Rim formation on crystal faces growing in confinement. J Cryst Growth 346:89-100. doi:10. 1016/j.jcrysgro.2012.03.019

104. Rudge JF, Kelemen PB, Spiegelman M (2010) A simple model of reaction-induced cracking applied to serpentinization and carbonation of peridotite. Earth Planet Sci Lett 291:215-227. doi:10.1016/j.eps1.2010.01.016

105. Scherer GW (1999) Crystallization in pores. Cem Concr Res 29:1347-1358. doi:10.1016/S0008-8846(99)00002-2

106. Scherer GW (2004) Stress from crystallization of salt. Cem Concr Res 34:1613-1624. doi:10.1016/j.cemconres.2003.12.034

107. Schutjens PMTM (1991) Experimental compaction of quartz sand at low effective stress and temperature conditions. J Geol Soc Lond 148:527-539

108. Shahidzadeh-Bonn N, Rafaï S, Bonn D, Wegdam G (2008) Salt crystallization during evaporation: impact of interfacial properties. Langmuir 24:8599-8605. doi:10.1021/la8005629

109. Smith I, Olstad E, Segura R (2011) Heightened regulations create demand for well abandonment services. Offshore 71(10):70-73

110. Steiger M (2005) Crystal growth in porous materials-I: the crystallization pressure of large crystals. J Cryst Growth 282:455-469. doi:10.1016/j.jcrysgro.2005.05.007

111. Steiger M (2005) Crystal growth in porous materials-II: influence of crystal size on the crystallization pressure. J Cryst Growth 282:470-481. doi:10.1016/j.jcrysgro.2005.05.008

112. Sun P, Grace JR, Lim CJ, Anthony EJ (2007) The effect of $\mathrm{CaO}$ sintering on cyclic $\mathrm{CO}_{2}$ capture in energy systems. AIChE $\mathrm{J}$ 53:2432-2442

113. Sun Z, Chi H, Fan L-S (2012) Physical and chemical mechanism for increased surface area and pore volume of $\mathrm{CaO}$ in water hydration. Ind Eng Chem Res 51:10793-10799

114. Taber S (1916) The growth of crystals under external pressure. Am J Sci 246:532-556

115. Taber S (1930) The mechanics of frost heaving. J Geol 38(4):303-317

116. Taylor HF, Famy C, Scrivener K (2001) Delayed ettringite formation. Cem Concr Res 31:683-693. doi:10.1016/S00088846(01)00466-5

117. Taylor HFW (1992) Cement chemistry. Academic Press, London

118. Tsui N, Flatt RJ, Scherer GW (2003) Crystallization damage by sodium sulfate. J Cult Herit 4:109-115. doi:10.1016/S12962074(03)00022-0
119. van Noort R, Spiers C, Kandianis M, Drury MR, Ten Grotenhuis SM (2010) Coupled geomechanical-geochemical aspects of $\mathrm{CO}_{2}$-sequestration in peridotites. In: AGU fall meeting abstracts, p 7

120. van Noort R, Spiers CJ, Peach CJ (2007) Effects of orientation on the diffusive properties of fluid-filled grain boundaries during pressure solution. Phys Chem Miner 34:95-112

121. van Noort R, Spiers CJ, Pennock GM (2008) Compaction of granular quartz under hydrothermal conditions: controlling mechanisms and grain boundary processes. J Geophys Res Solid Earth 113(B12206):1-23

122. van Noort R, Visser HJM, Spiers CJ (2008) Influence of grain boundary structure on dissolution controlled pressure solution and retarding effects of grain boundary healing. J Geophys Res Solid Earth 113(B03201):1-15

123. Visser HJM, Spiers CJ, Hangx SJT (2012) Effects of interfacial energy on compaction creep by intergranular pressure solution: theory versus experiments on a rock analog $\left(\mathrm{NaNO}_{3}\right)$. J Geophys Res. Solid Earth 117(B11211):1-15

124. Voorhees HR, Sliepcevich CM, Freeman JW (1956) Thickwalled pressure vessels. Ind Eng Chem 48:872-881. doi:10. 1021/ie50557a026

125. Warne P (2004) Decommissioning-North Sea. OGEL 2. http:// www.ogel.org/article.asp?key=1254. Accessed 21 Mar 2017

126. Weyl PK (1959) Pressure solution and the force of crystallization: a phenomenological theory. J Geophys Res 64:2001-2025

127. Whittaker S, Rostron B, Hawkes C, Gardner C, White D, Johnson J, Chalaturnyk R, Seeburger D (2011) A decade of $\mathrm{CO}_{2}$ injection into depleting oil fields: monitoring and research activities of the IEA GHG Weyburn-Midale $\mathrm{CO}_{2}$ Monitoring and Storage Project. Energy Procedia 4:6069-6076. doi:10. 1016/j.egypro.2011.02.612

128. Wolter A, Luger S, Schaefer G (2004) Zur Kinetik der Hydratation von Branntkalk. ZKG Int 57:60-68

129. Wolterbeek TKT, Hangx SJT, Spiers CJ (2016) Effect of $\mathrm{CO}_{2^{-}}$ induced reactions on the mechanical behaviour of fractured wellbore cement. Geomech Energy Environ 7:26-46. doi:10. 1016/j.gete.2016.02.002

130. Wolterbeek TKT, Peach CJ, Raoof A, Spiers CJ (2016) Reactive transport of $\mathrm{CO}_{2}$-rich fluids in simulated wellbore interfaces: flow-through experiments on the $1-6 \mathrm{~m}$ length scale. Int $\mathrm{J}$ Greenh Gas Control 54:96-116. doi:10.1016/j.ijggc.2016.08.034

131. Yasuhara H, Elsworth D, Polak A (2003) A mechanistic model for compaction of granular aggregates moderated by pressure solution. J Geophys Res Solid Earth 108(B11):1-13

132. Zhang M, Bachu S (2011) Review of integrity of existing wells in relation to $\mathrm{CO}_{2}$ geological storage: What do we know? Int $\mathrm{J}$ Greenh Gas Control 5:826-840. doi:10.1016/j.ijggc.2010.11.006 